\title{
Vehicle to Grid Impacts on the Total Cost of Ownership for Electric Vehicle Drivers
}

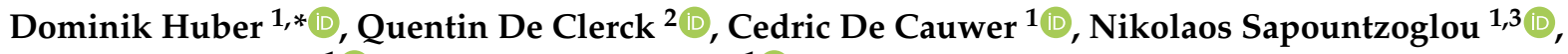 \\ Thierry Coosemans ${ }^{1}$ (D) and Maarten Messagie ${ }^{1(1)}$
}

1 MOBI Reserach Group, ETEC Department, Vrije Universiteit Brussels, Pleinlaan 2, 1050 Brussels, Belgium; cedric.de.cauwer@vub.be (C.D.C.); nikolaos.sapountzoglou@vub.be (N.S.); thierry.coosemans@vub.be (T.C.); maarten.messagie@vub.be (M.M.)

2 MOBI Reserach Group, BUTO Department, Vrije Universiteit Brussels, Pleinlaan 2, 1050 Brussels, Belgium; quentin.de.clerck@vub.be

3 Innovation Section, European Network of Transmission System Operators for Electricity (ENTSO-E), Rue de Spa 8, 1000 Brussels, Belgium

* Correspondence: Dominik.Huber@vub.be; Tel.: +32-2629-3843

Citation: Huber, D.; De Clerck, Q.; De Cauwer, C.; Sapountzoglou, N.; Coosemans, T.; Messagie, M. Vehicle to Grid Impacts on the Total Cost of Ownership for Electric Vehicle Drivers. World Electr. Veh. J. 2021, 12, 236. https://doi.org/10.3390/ wevj12040236

Academic Editor: Taha Selim Ustun

Received: 23 September 2021

Accepted: 8 November 2021

Published: 11 November 2021

Publisher's Note: MDPI stays neutral with regard to jurisdictional claims in published maps and institutional affiliations.

Copyright: (c) 2021 by the authors. Licensee MDPI, Basel, Switzerland. This article is an open access article distributed under the terms and conditions of the Creative Commons Attribution (CC BY) license (https:// creativecommons.org/licenses/by/ $4.0 /)$.

\begin{abstract}
Electric vehicles (EV) are foreseen as one major technology toward decarbonizing the mobility sector. At the same time, Vehicle to Grid (V2G) technology opens a new market for EV owners. This article identifies the impacts of providing V2G services on the Total Cost of Ownership (TCO) of EVs. Thus, we studied EVs in private, semi-public and public charging cases, considering two different V2G revenue streams. The included V2G services were: (i) local load balancing to balance the peaks and valleys of the electricity demands of buildings and (ii) an imbalance service to enhance grid stability. In this paper, the impact of these two V2G services is quantified and considered in the TCO calculations. To the authors' knowledge, no comparable study incorporating the same V2G services exists in the literature. The TCO is calculated with real-life data for four different EVs currently available in the market. As a result, the V2G TCO ranges from $€ 33.167$ to $€ 61.436$ over an average of nine years for the Flanders region (Belgium).
\end{abstract}

Keywords: total cost of ownership; Vehicle-to-Grid; charging of electric vehicles; passenger cars; electric vehicles

\section{Introduction}

In 2019, greenhouse gases (GHG) emissions from domestic transportation accounted for roughly $22.98 \%$ (excl. international shipping and aviation) while $26.62 \%$ of GHG emissions were generated by energy supply. Thus, these two sectors were responsible for roughly 50\% of GHG emissions in 2019 [1]. To decarbonize the energy supply sector, great potential is expected from the upscale of renewable energy carriers. To lower the environmental impacts of the transportation sector, electric vehicles (EVs) are foreseen as one potential solution.

The mass introduction of EVs can address the decarbonization of both the transport and energy supply sector: Vehicle-to-Grid (V2G) technology is a concept in which EVs are used, in addition to the traditional transportation service, as a mobile storage application for providing various grid services [2,3]. Thereby, stored-but unused-electricity in the EV can be discharged back into the grid or used for local consumption. Thus, EVs can, at the same time, reduce the emissions of the transportation sector when fueled with an electricity mix mostly built of renewable energy carriers and help to overcome the fluctuation problem of renewable energy carriers.

A considerable number of publications already aim at the quantification of economic benefits of a situation where EVs are used as mobile storage devices. However, the outcomes of these studies indicate different implications. Some studies argue that V2G technology will reveal economic benefits for different stakeholders. For example, an EV 
charge/discharge day-ahead optimization for frequency and voltage regulation services, including a battery degradation model, was developed in [4]. Subsequently, different case studies were applied to validate the developed model.

Researchers found that participation in these V2G services would result in a significant decrease of charging costs. As a conclusion, the EV owner gains more when providing frequency support while the aggregator benefits from voltage support [4]. Additionally, a V2G simulator by modelling a standard IEEE30 network to analyze two scenarios, with and without V2G, was investigated in [5]. Benefits for EV owners of V2G participation are included in the form of avoided charging costs. The paper revealed that the developed control strategy with $\mathrm{V} 2 \mathrm{G}$ can decrease charging costs by $13.6 \%$ [5].

On the other hand, studies also claim that V2G technology does not result in an overall cost decrease. The future financial and social consequences of standard and fast charging in a V2G context, including renewable energy production, were studied in [6]. Other than expected, they found that fast charging led to a lower utilization of electricity generated by RES and did not result in a significant reduction of charging costs [6]. Furthermore, another study evaluated the compensation required for reimbursement of EV owners performing V2G ancillary services [7]. For this reason, the authors combined a battery degradation model, a power train model and a cost comparison of conventional and EVs [7]. Various sensitivity cases revealed that providing V2G ancillary services is not cost-efficient under the current legislation and market conditions [7].

At the same time, some studies outline what aspects should be addressed for successful V2G implementation. The electricity costs of a car park with $50 \mathrm{EV}$ charging slots allowing V2G interactions was examined in [8]. By extending an energy cost model to include the battery degradation cost and incomes from rebates of the energy company policy, the importance of appealing feed in tariffs for EV users, the improvement of battery performance and governmental policy were highlighted as stimulators for V2G [8].

Moreover, a qualitative meta-analysis considering 340 published cases to reveal key drivers of economic benefits when utilizing plug-in EVs as mobile storage device was conducted in [9]. While performing their research, the authors found great inconsistencies and contradictions in the existing literature. Based on the study, the authors observed that the highest benefits for EV owners can be obtained when providing load levelling services and secondary frequency services [9]. In this context, it is also worth considering a macro perspective.

The costs and benefits of a V2G peak shaving service in Shanghai for four different vehicles were explored [10]. In their V2G model for peak shaving and valley filling, they reflected different stakeholders along the value chain, such as power generation companies, grid companies and EV users. While generation companies highly benefit from the V2G services, grid companies have to bear highest investments and, therefore, always obtain negative net incomes. The net incomes of EV users depend on the underlying tariffication. Overall, it was found that incomes along the value chain are distributed unequally under current market structures [10].

Total Cost of Ownership (TCO) calculations compare investments financially by considering the costs revealed over a vehicle's lifetime [11]. Over the last decade, TCO has been widely applied for comparisons of different vehicle types. An early TCO study of different vehicle types was conducted in [12]. Vehicles were studied for Flanders, the Flemish speaking part of Belgium and clustered into city as well as medium and premium car segment. The authors concluded that EVs were not cost attractive in the city and medium car segments [12]. Next, the TCO for EVs when participating in V2G was calculated [13]. As a charging location, a household with a PV panel was chosen and estimated a fixed electricity feedback to the grid of $1500 \mathrm{kWh}$ per year [13].

The resulting decrease had a diminishing effect on the TCO of only $1-2.59 \%$ [13]. Furthermore, the scope of the previous TCO study was extended to a total cost of society (TCS) calculation by adding climate change, air pollution, noise, accidents and congestion [14]. In addition to the TCS, different vehicle behaviours were considered, resulting in 
a persona-based approach [12]. While the TCO of EVs were higher than for conventional vehicles, the TCS showed the opposite due to the low climate change and air pollution impacts of EVs.

Outside of a Belgium scope, the total costs of ownership are also calculated with other geographic considerations, e.g., a TCO within a German context [15]. Electric and conventional vehicles were clustered into small, medium and large size classes, and different driver profiles were proposed. Contrary to the previous studies, occurring costs were not classified as costs at the purchase time, operating and non-operating costs but into capital expenditures (CAPEX) and operating expenditures (OPEX). It was observed that EVs without subsidies are hardly competitive with conventional vehicles [15].

Another publication proposed an EV TCO forecasting framework based on literature reviews and interviews [16]. As a result, 34 influencing factors of the TCO were considered in that study [16]. Taking a macroeconomic perspective, they concluded that EVs will not become much cheaper than conventional vehicles in the future [16]. Additionally, the authors predicted that the TCO of EVs will become more complex than adding up only single cost components [16].

However, none of the presented TCO studies incorporated different V2G services provided at different charging cases. As outlined in the previous paragraphs, there is already some literature aiming on the quantification of the impacts of V2G services. However, little is known regarding how such potential V2G services would impact individual EV drivers financially. The total cost of ownership calculation proposes one method to understand the impact of V2G services on the financial aspects of individual EV owners. Therefore, the aim of this study is to integrate V2G impacts into the TCO and quantify potential V2G effects by identifying its costs and revenues. To the authors' knowledge, no study exists that assesses the outlined charging cases and service possibilities given by V2G.

To investigate the outlined research, this paper is structured in the following way: in Section 2, the methodological background of the TCO, the tarifficaiton and the V2G impacts are provided followed by a description of the charging cases, the general assumptions and specific costs in Section 3. Section 4 presents the TCO results, while Section 5 presents a sensitivity analysis. Finally, the paper is concluded in Section 6, with the limitations of this research and our discussion addressed in Section 7.

\section{Method}

\subsection{Total Cost of Ownership Calculation}

The Total Cost of Ownership Calculation is a methodology [11] that accounts for all costs occurring during the ownership of a good and allows a comparison of the affordability of different goods. Hence, this tool allows one to understand the actual cost when purchasing a particular good or service [17]. Generally, TCO calculations can be distinguished in two different types: (i) one that aims at identifying the costs a consumer has to face when owning a particular good and (ii) another that strives for a broader perspective where, besides considering the costs a consumer has to bear when buying a good, it also accounts for the costs for society and the environment [12]. In this study, the TCO was conducted from a consumer perspective following Equation (1):

$$
\mathrm{TCO} / \mathrm{km}=\frac{\sum C_{t}}{m_{t}},
$$

where

- $\quad$ TCO is the Total Cost of Ownership (TCO) $(€ / \mathrm{km})$,

- $\quad C$ are the costs occurring during the ownership $(€)$,

- $\quad t$ is the time expressed as the number of years (years) and

- $\quad m$ is the driven mileage during the ownership time expressed in $\mathrm{km}(\mathrm{km})$. 
Moreover, the TCO of standard EVs were calculated to enable a comparison with the TCO results of EVs providing V2G. Therefore, no internal combustion engine vehicles were included.

\subsection{Relevant Costs}

The TCO considers the purchase costs and costs appearing over the goods' lifetime $[14,18]$. For vehicles particularly, the TCO consists of costs at the purchase time, operational costs and non-operational costs. Costs at the purchase time would represent the initial investment that EV owners would have to make when acquiring an EV. Next to hardware costs, such as the purchase cost of the EV and the charging station, administrative costs should also be taken into account, for example registration tax.

Operational costs are costs that occur from driving the vehicle. Depending on the propulsion technology, these costs can either be fuel or electricity costs. Additionally, the height of operational costs is determined by the driving distance. The third category, non-operational costs, groups all other costs not included in the previous two; such costs can be related to the operation and maintenance of the vehicles. All three different cost types are presented in detail in Table (Table 1).

Table 1. Overview of the considered costs for the TCO calculation [12,14,19].

\begin{tabular}{ccc}
\hline Cost at Purchase Time & Operational Costs & Non-Operational Costs \\
\hline EV purchase price & Costs for electricity consumption & Insurance premiums \\
Charging station purchase price & Maintenance costs \\
Governmental premium & Tires replacement costs \\
Registration tax & Battery replacement costs \\
& Annual road tax \\
& Costs technical control \\
& Costs fines \& parking \\
\hline
\end{tabular}

\subsection{Net Present Value}

All arising costs over the vehicle's lifetime have to be recalculated in order to assess their future value at the present time. Here, one can distinguish between two different types of future costs [12]. Equation (2) illustrates how to calculate the net present value of one-time costs, while Equation (3) can be used to identify recurring costs [20].

$$
\begin{gathered}
N P V=A_{t} \frac{1}{(1+r)^{t}} \\
N P V=A_{0} \times \frac{(1+r)_{t}-1}{r \times(1+r)^{t}}
\end{gathered}
$$

where

- $\quad N P V$ is the net present value $(€)$,

- $A_{t}$ is the one-time costs at time $t(€)$,

- $A_{0}$ is the annual reoccurring cost $(€ /$ year),

- $\quad r$ is the real discount rate (\%p.a.) and

- $t$ is the time expressed as the number of years (years).

When calculating the net present value, either a real discount rate (excluding inflation) or a nominal discount rate (including inflation) can be used. Here, a real discount rate is considered to avoid accounting for inflation [12].

\subsection{Tariffication}

\subsubsection{System Description}

For this study, special attention was given to the charging locations with installed photovoltaics (PV). At the same time, electricity can also be requested from the Belgian grid. In the case where the PV installations produce excess electricity, e.g., during midday 
when solar irradiation can be at its highest and electricity consumption at its lowest, these quantities can be fed back into the grid. By introducing EVs into that system, the impacts are twofold: (i) additional electricity demand will occur as the EV has to be charged, either by self-generated PV electricity or by grid electricity and (ii) these EVs can function as mobile electricity storage devices. As EVs are parked most of their time, the stored electricity can be discharged and used in other ways. In this study, the discharged electricity from the EVs is used either for local load balancing (LLB) or to provide imbalance services (IS).

In the case of LLB, the discharged electricity is directly used at the charging location [21]. Thereby, the EV provides stored electricity for direct consumption at the location, avoiding requesting electricity from the grid and, thus, increasing the self-consumption of PV-generated electricity. In other words, the EV helps to store excess electricity generated by the PV installation and supplies the same electricity when the electricity demand of the charging location is increasing again. The self-consumption SC in percentage of the charging location can be calculated as follows [22]:

$$
S C(\%)=e_{S P V} / e_{P V},
$$

where

- $e_{S P V}$ is the amount of electricity in $\mathrm{kWh}$ that is consumed directly by the charging location (kWh), while

- $\quad e_{P V}$ is the amount of electricity in $\mathrm{kWh}$ that is generated by the PV installation at the charging location $(\mathrm{kWh})$.

As a second option, the discharged electricity from the EVs can also be used in the imbalance market. In this case, the electricity is not used at the charging location but will be utilized for grid balancing. Generally, balance responsible parties (BRP) are responsible to keep the offtake and injection of a certain region in balance. In case these BRPs fail to do so, the Belgian transmission system operator (TSO), Elia, steps in and aims at limiting the occurring imbalances between electricity generation and consumption. For this reason, Elia established a market where balancing service providers (BSP) offer flexibility services to Elia. Such flexibilities can be offered in three different product types: (i) primary control reserve (frequency containment), (ii) secondary control reserve (frequency restoration with automatic activation) and (iii) tertiary control reserve (frequency restoration with manual activation) [23].

\subsubsection{Tariff Calculation}

Applying a simple household electricity price or an electricity price for professional clients, would not reflect the described charging locations and the potential V2G service EVs could provide. For this reason, particular tariffs are determined in this section. Overall, three different tariffs were determined for each charging location:

- one tariff reflects a system where a standard charging situation of EVs is reflected,

- another tariff for a system that allows LLB and

- $\quad$ one tariff for IS.

Detailed explanations about the separate charging cases are given in Section 3.1. Three different prices were defined: (i) the tariffs itself represent the values that are utilized to calculate the operational costs in Euro per $\mathrm{kWh}$, (ii) the cost of electricity describes the investments of the location holder to set up the charging location including all the required installations in Euro per $\mathrm{kWh}$ and (iii) the marginal costs are adding the costs for charging infrastructure up on the cost of electricity to refund the costs of charging in Euro per $\mathrm{kWh}$. Thereby, the costs for the charging stations will fully be borne by the EV owner.

All these prices result from internally developed cost algorithm of our research group, which is not part of this study. As these internal calculations are specifically determined for LLB, the standard case without EV charging was utilized considering the installation of V2G chargers. Thereby, the case of providing imbalance services is determined and all hereafter mentioned formulas are applicable for both LLB and IS. 


\section{Load Demand}

First, the overall load demand $L_{C L}$ in $\mathrm{kWh}$ was calculated as follows:

$$
L_{C L}=\sum\left(e_{G S}+e_{G I}+e_{P V}\right)
$$

where

- $e_{G S}$ represents the amount of electricity that the charging location is requesting from the grid (kWh/year),

- $\quad e_{G I}$ stands for the excess electricity generated by the PV installation and is fed back into the grid ( $\mathrm{kWh} /$ year), and

- $\quad e_{P V}$ is the amount of electricity that is generated by the PV installations (kWh/year).

All values are given in $\mathrm{kWh} /$ year. Values for PV production are estimated and scaled to the PV size of each charging location. The total grid supply and total grid injection is calculated based on internal calculations performing energy balance with an energy cost minimization algorithm. By applying the prices provided in Table 2, the same internal calculation determined the overall electricity bill $C_{G E}$ in Euro per year for the particular location.

Table 2. Electricity prices used in the internal calculations to perform energy balance with an energy cost minimization algorithm (source: all prices originate from an industrial site in Brussels).

\begin{tabular}{cccc}
\hline Price Type & Injection Price & Supply Price & Peak Price \\
\hline Unit & $€ / \mathrm{kWh}$ & $€ / \mathrm{kWh}$ & $€ / \mathrm{kWh}$ \\
On-peak & -0.035 & 0.128 & 2.35 \\
Off-peak & -0.029 & 0.110 & 2.35 \\
\hline
\end{tabular}

\section{PV Costs}

Next to the overall electricity bill, the costs of the PV installations have to be taken into account as well. The annual costs of the PV installation can be hence calculated as follows:

$$
C_{P V}(€ / \text { year })=\frac{C A P E X_{P V} \times A}{t_{P V}}-G C \times e_{P V}+O P E X_{P V} \times A,
$$

where

- $C_{P V}$ represents the total cost of PV installation ( $€ /$ year),

- $\quad C A P E X_{P V}$ stands for the capital expenditures of the PV installation $(€ / \mathrm{kWp})$,

- $A$ is the PV size $(\mathrm{kWp})$,

- $t_{P V}$ is the lifetime of the PV installation (years),

- $\quad G C$ are the green certificates $(€ / \mathrm{kWh})$, and

- $O P E X_{P V}$ is the operational expenditures of the PV installations $(€ / \mathrm{kWp} /$ year).

Chargers

The last cost part addresses the costs of the charging infrastructure. For this study, two different types of chargers are differentiated: (i) one charger for standard charging of the EVs and (ii) a bidirectional charger allowing V2G interactions. The annual costs of the standard chargers $C_{S}$ in ( $€$ /year) can be determined as follows:

$$
C_{S}=\frac{N_{C} \times S_{C} \times C A P E X_{C}}{t_{C S}}
$$

where

- $\quad N_{C}$ is indicating the number of chargers installed at the charging location (Number of chargers),

- $S_{C}$ is the size of the standard chargers $(\mathrm{kW})$,

- $\quad C A P E X_{C S}$ is the capital expenditures of the standard chargers $(€ / \mathrm{kW})$ and 
- $\quad t_{C S}$ is the lifetime of the chargers (years).

In order to allow V2G interactions, the charging stations need to be upgraded. Due to the novelty of V2G technology, current prices for V2G chargers are still extremely high. Contrary, lower values are found in literature and these values are applied in this study with the limitation that these costs represent future costs that are currently not available in the market. Accordingly, upgrade costs of $€ 1245.00$ for the charging stations are considered [24]. These costs of $€ 1245.00$ correspond to a $15-\mathrm{kW}$ AC bi-directional charger [24].

To ensure good functioning and account for part replacement of the V2G charging stations, an annual charge for maintenance of $5 \%$ of the total investment cost for the charging station is considered [24]. Maintenance costs of the infrastructure can be retrieved by adding the purchase costs of a standard charger $C_{S}$ and the upgrade costs of these chargers to allow V2G participation $C_{V 2 G C}$. Thus, the costs of the V2G chargers $C_{V 2 G C}$ in (€/year) can be calculated as follows:

$$
C_{V 2 G C}=\frac{N_{V 2 G C} \times S_{V 2 G C} \times C A P E X_{V 2 G C} \times\left(1+C_{V 2 G C M}\right)}{t_{V 2 G C}},
$$

where

- $\quad N_{V 2 G C}$ stands for the numbers of $\mathrm{V} 2 \mathrm{G}$ chargers installed at the charging location (Numbers of chargers),

- $S_{V 2 G C}$ is the size of the V2G chargers $(\mathrm{kW})$,

- $C A P E X_{V 2 G C}$ are the capital expenditures of the $\mathrm{V} 2 \mathrm{G}$ chargers $(€ / \mathrm{kW})$,

- $\quad C_{V 2 G C M}$ is the maintenance costs for V2G chargers (\%) and

- $t_{V 2 G C}$ refers to the lifetime of the V2G chargers (years).

\section{Cost of Electricity}

The different cost types are summarized in the total costs of the charging location $C_{t C L}$ in (€/year):

$$
\begin{gathered}
C_{t C L}=C_{G E}+C_{P V}+C_{S} \\
C_{t C L}=C_{G E}+C_{P V}+C_{V 2 G C} .
\end{gathered}
$$

In a subsequent step, the cost of electricity $C_{e}$ in $(€ / \mathrm{kWh})$ of each charging location can be calculated as follows:

$$
C_{e}=\frac{C_{t C L}}{L_{C L}}
$$

\section{Marginal Costs}

In the case where the location holder is not the EV owner, the location holder would likely install charging stations only to attract more customers and fulfil their charging needs. Consequently, the location holder would not charge the EV owners with the cost of electricity, but would instead charge the EV owners with the marginal costs of installing the chargers at the location. The marginal costs $C_{m}$ in $(€ / \mathrm{kWh})$ are determined as followed:

$$
C_{m}=\frac{C_{t C L}^{\text {nochargers }}-C_{t C L}^{V 2 G / \text { standard }}}{E_{C}},
$$

where

- $\quad C_{t C L}^{\text {nochargers }}$ are the total costs of the charging location without any chargers ( $€ /$ year),

- $\quad C_{t C L}^{V 2 G / \text { standard }}$ represents the total costs of the charging location with either V2G or standard chargers (€/year) and

- $E_{C}$ is the electricity demand of the installed charging stations ( $\mathrm{kWh} /$ year). 
By distinguishing cost of electricity and marginal costs, two different prices are deliberated to reflect differences in charging cases, for example to distinguish between private and semi-public charging.

Tariffs

Depending on the charging location, either the cost of electricity or the marginal costs are used and profit margins of involved stakeholders along the value chain were added up to derive the final tariffs. In the case of the semi-public and public charging case, stakeholders other than the EV owner and the location holder are active. Involved stakeholders along the value chain for charging were identified from [25]. In this study, three main stakeholders were considered: (i) a location holder (LH), (ii) a charge point operator (CPO) and (iii) a mobility service provider (MSP).

We assume that the LH is the owner of the charging location. A CPO would be responsible for the hardware infrastructure and its maintenance, whereas a MSP would be taking care of the charging transaction. As these relevant stakeholders participate in the EV market, they rightfully offer their service while charging a commission. As no literature about the profit margins of these stakeholders is available at the current stage, the profit margin (PM) of each stakeholder is assumed to be $10 \%$ of the cost of electricity or the marginal costs. Thus, the following Equations for tariff calculation are defined:

$$
\begin{aligned}
& T=C_{e} \times P M_{L G} \times P M_{C P O} \times P M_{M S P}, \\
& T=C_{m} \times P M_{L G} \times P M_{C P O} \times P M_{M S P},
\end{aligned}
$$

where

- $T$ is the tariff $(€ / \mathrm{kWh})$,

- $C_{e}$ is the cost of electricity $(€ / \mathrm{kWh})$,

- $C_{m}$ is the marginal cost of electricity (€/ $\left.\mathrm{kWh}\right)$,

- $\quad P M_{L H}$ is the profit margin (PM) of the location holder (LH) (\%),

- $\quad P M_{C P O}$ is the profit margin of the charge point operator (CPO) (\%) and

- $\quad P M_{M S P}$ is the profit margin of the mobility service provider (MSP) $(\%)$.

\subsection{Vehicle-to-Grid Impact}

The overall Vehicle-to-Grid (V2G) impact is defined as the sum of all V2G benefits deducted by the $\mathrm{V} 2 \mathrm{G}$ costs:

$$
V 2 G_{\text {impact }}=V 2 G_{\text {benefit }}-V 2 G_{\text {costs }} .
$$

2.5.1. Vehicle-to-Grid benefits

V2G benefits can then further be differentiated into direct and indirect compensation:

$$
V 2 G_{\text {benefits }}=\sum{ }_{t}\left(B_{S E}+C M_{i}+C M_{d}\right),
$$

where

- $B_{S E}$ is the benefit of saved electricity costs from the grid $(€)$,

- $\quad C M_{i}$ is indirect compensation $(€)$ and

- $\quad C M_{d}$ is direct compensation (€).

The benefits of saved electricity costs from the grid $B_{S E}$ occur at private charging locations due to increase of the self-consumption rate. Such benefits are determined as followed:

$$
B_{S E}=\left(S C_{V 2 G}-S C_{S t a n d a r d}\right) \times e_{G r i d}
$$

where

- $S C_{V 2 G}$ is the self-consumption of PV electricity at a charging location where V2G services is used for LLB (\%), 
- $\quad S C_{\text {Standard }}$ is the self-consumption of PV electricity at a charging location with standard EV charging (\%) and

- $\quad e_{\text {Grid }}$ represents the average electricity household price in Belgium over the last 10 years $(€ / \mathrm{kWh})$.

The difference of $S C_{V 2 G}$ and $S C_{\text {Standard }}$ is understood as the avoided grid electricity at the charging location. Thus, to quantify the avoided grid electricity, this amount is then multiplied by the average electricity household price $e_{\text {Grid }}$ of Belgium over the last ten years. A price of $€ 0.24 / \mathrm{kWh}$ is utilized [26]. Applying the average household price presents another simplification: by utilizing the EV as a mobile storage device, the grid electricity could be avoided, occurring at different time slots. Thus, it would be appropriate to use prices corresponding to the time where the electricity normally would have been consumed from the grid (e.g., off- and on-peak electricity prices).

$C M_{i}$ represents indirect compensation and $C M_{d}$ describes direct compensation.

The EV owner will experience indirect compensation due to the difference in the tariffs. Therefore, indirect compensation $C M_{i}$ can be calculated as provided by Equation (6):

$$
V 2 G_{C M_{i}}=\triangle\left(C_{V 2 G t}-C_{S t}\right),
$$

where

- $\quad V 2 G_{C M_{i}}$ is the indirect compensation from providing V2G services (€)

- $\quad C_{V 2 G t}$ is the tariff for a charging case, where V2G (LLB/IS) is provided ( $\left.€ / \mathrm{kWh}\right)$ and

- $\quad C_{S t}$ is the tariff for a standard charging case $(€ / \mathrm{kWh})$.

Indirect compensation from $\mathrm{V} 2 \mathrm{G}$ service $V 2 G_{C M_{i}}$ can be understood as the difference between tariff for a standard charging case $\left(C_{S e}\right)$ and the tariff determined for the specific charging cases when providing V2G services $\left(C_{V 2 G e}\right)$.

In addition to indirect compensation, the EV owner can also experience direct compensation. Direct compensation is only applicable when IS service is provided:

$$
V 2 G_{C M_{d}}=\sum t\left(r_{I S}\right),
$$

where

- $\quad r_{I S}$ are the revenues from IS services (€/year).

Here, $C M_{d}$ stands for direct compensation and IS revenues, $r_{I S}$, were directly taken from [27]. According to these authors, 'in the year 2017, [...] in total there was more overproduction of energy than underproduction. Therefore, most of the days the vehicles got charged just by balancing the grid at night' [27]. Following this description, we deem that $60 \%$ of the energy charged for the IS cases is done just by balancing the grid and does not have additional costs for charging. To take these circumstances into account, we assume that the EV owner will only pay $40 \%$ of the base case electricity costs when providing IS.

Normally, the EV owner should be reimbursed for the additional wear of his EV battery due to V2G participation. However, the still rather early research on the V2G impacts on battery degradation currently does not come to a consensus on the impact of such services on the battery lifetime. On one side, various research has not identified additional wear of batteries when V2G services are provided [28-30], while on the other hand, the literature clearly revealed additional battery degradation when participating in V2G [28,31-34]. As all of these studies are still at a rather early stage and much more investigation is required to obtain reliable results on the impact of V2G activities on the traction battery of EVs, no reimbursement for the additional use of the EV battery is applied in this study.

\subsubsection{Vehicle-to-Grid Costs}

The following formula to obtain $V 2 G_{\text {costs }}$ in $(€)$ can be used:

$$
V 2 G_{\text {costs }}=\sum_{t}\left(C_{e m}\right)
$$


where

- $C_{e m}$ represents the costs for the energy manager in a private charging case $(€)$.

Such costs can be calculated following Equation (21):

$$
C_{e m}=0.4 \times B_{S E},
$$

These costs, $C_{e m}$ can be calculated by multiplying the benefits of saved electricity costs from the grid $B_{S E}$ by $40 \%$.

\section{Case Study}

Obtained data are retrieved either from primary or secondary literature (e.g., via websites of manufacturers, car dealers, AXA insurance, Michelin, QTeam, Flemish government, etc.). No project data are included.

\subsection{Charging Cases}

\subsubsection{Qualitative Description of the Charging Cases}

Private Charging

From a technological perspective, the charging location considered in this case comprises of a $3.8 \mathrm{kWp}$ PV installation and one $22 \mathrm{~kW}$ charging station. Additionally, there is access of the charging location to the electric grid. The EV owner connects his EV to a charging station installed on his private property/home. Here, both the tariff for standard and for LLB are $0.22 € / \mathrm{kWh}$, as the higher costs for V2G chargers are offset by the benefit of providing electricity from the EV battery. Thus, the EV owner benefits when providing LLB from utilizing the discharged electricity from his EV and increasing his self-consumption rate.

As a consequence, the EV owner will request less electricity from the grid and will experience a decrease in his electricity bill. The decrease can be quantified as described in Equation (5). This decrease is charged with costs for an energy management of $40 \%$ of the benefits of avoided grid electricity. Additionally, the EV owner can also experience an indirect compensation $C M_{I}$ (see Equation (6) described in the previous section), if the tariff for LLB in a private charging case is below the standard charging case.

Alternatively to providing LLB, the EV owner can discharge electricity from the EV battery back into the grid to ensure grid stability. Thereby, the DSO or TSO will reimburse the EV owner for providing electricity from its battery. When EV owners supply IS at their private charging stations, the standard electricity costs plus additional costs for the V2G chargers are applicable. Hence, the tariff is $0.23 € / \mathrm{kWh}$. When participating in the imbalance market, the EV owners of a Nissan Leaf, a BMW i3, a Hyundai Kona and a Renault Zoe are estimated to receive revenues of $€ 1176.00, € 1176.00, € 1166.00$ and $€ 1166.00$ [27].

These impacts can be quantified as direct compensations $C M_{d}$ (see Equation (7)), and it is further assumed that these revenues could be applied simultaneously among all charging cases. As the charging station is on the private property of the EV owner, only he can access the charging station. Thus, no third party like a charge point operator (CPO), mobility service provider (MSP) or a location holder (LH) is involved for granting access.

For this reason, the EV owner will receive the maximum reimbursement and benefits will not be compromised by profit margins of other stakeholders. Similar to LLB, the direct compensation for IS is reduced by the costs for an energy management system of $40 \%$ of the obtained direct compensations from IS. All payments and compensations in a private charging case are summarized in Figure 1. 


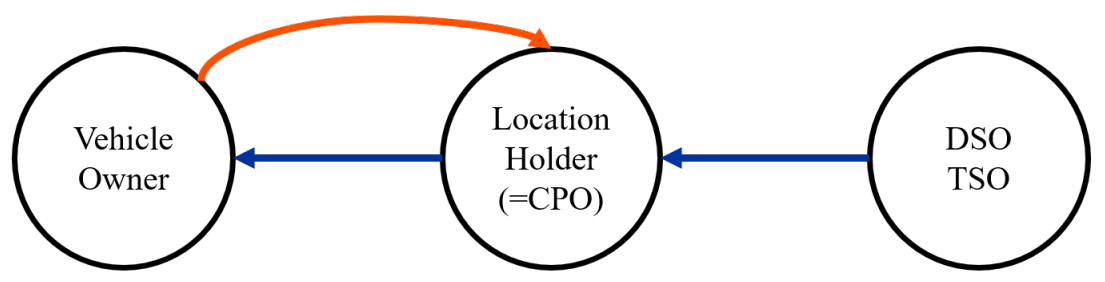

Cost of charging (payment)
V2G service compensation
(direct and indirect)

Figure 1. Definition of a private charging case (following [25], own compilation).

\section{Semi-Public Charging}

The EV owner is not charging at his private property in this case, but charges at another charging station. Here, the EV is charged, for example, in a shopping mall, where the owner of the shopping mall wants to install a charging station. This charging location can be described as a building generating its own load. To supply its electric demand, a $12 \mathrm{kWp}$ PV installation is in place next to electricity demanded from the grid. In this case, the LH simultaneously provides the charging location and acts as a CPO. For this case, it is assumed that the LH has acquired 12 charging stations.

When it comes to V2G services, the LH will increase the consumption of its selfgenerated PV electricity and thereby avoid to demand electricity from the grid. The calculation of such benefits is outlined in Equation (5). These benefits would normally not be achieved without the introduction of EVs providing LLB. For this reason, the resulting benefits should be accounted to the EV owners. Assuming that the LH does not own any EVs occupying the defined number of chargers, the case of semi-public charging case does not reflect the benefits from increased self-consumption. In general, EV owners are charged with a tariff of $0.25 € / \mathrm{kWh}$ for standard charging, while the charging price when performing LLB makes up $0.34 € / \mathrm{kWh}$.

These tariffs consist of the cost of electricity of the existing energy system, e.g., the shopping mall, plus the marginal costs of installing the charging stations. The price difference between the standard and LLB can be traced back to higher tariff for V2G charging station costs. Compared to the private charging case, the charging station utilization in a semi-public charging case is estimated to be much lower, and, consequently, the marginal costs in a semi-public charging case are higher. Under normal utilization of the V2G charging stations, a cheaper tariff compared to standard charging would be offered to the EV owners. When providing IS, the tariff is $0.35 € / \mathrm{kWh}$ and it is compiled of cost of electricity of $0.12 € / \mathrm{kWh}$ and the marginal costs for the V2G chargers.

As the charging stations in this case are accessible to the public, a MSP is required to manage the access of the EV users. Obtained revenues from IS will be reduced by the profit margins of the LH $(10 \%)$ and the MSP $(10 \%)$. All payments and compensations in a semi-public charging case are summarized in Figure 2. 


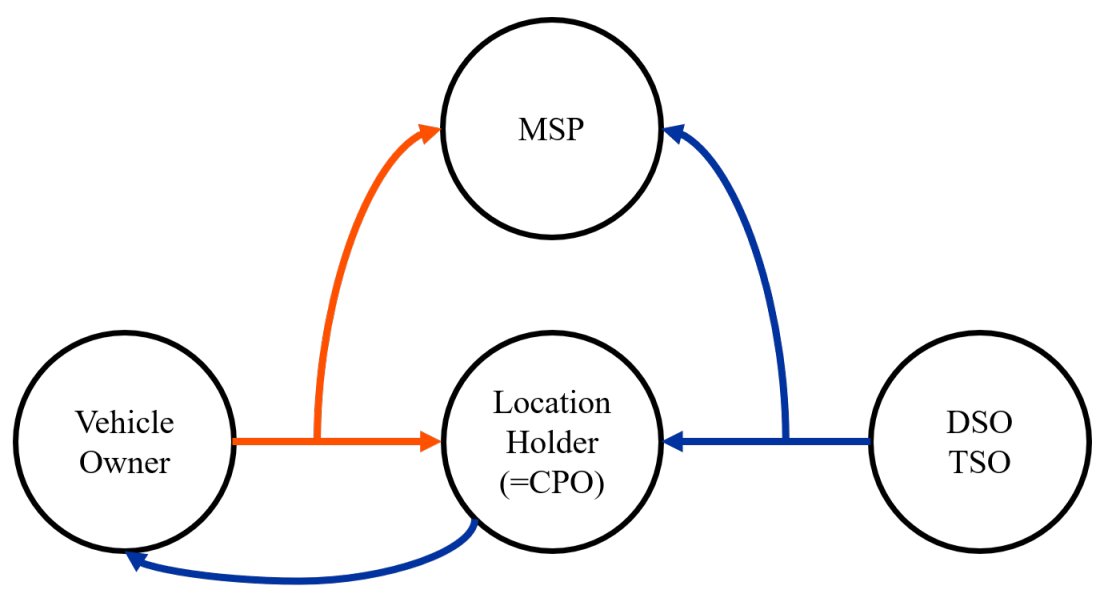

Cost of charging (payment)

V2G service compensation (direct and indirect)

Figure 2. Definition of a semi-public charging case (following [25], own compilation).

\section{Public Charging}

Public charging stations of a public charging hub are utilized for charging the EVs in this case. In terms of installation, this charging case does not distinguish from the semi-public charging case. At both locations, 12 charging stations and a PV installation of $12 \mathrm{kWp}$ are set up. The difference of these two locations is that the charging location in a public charging case has no electric consumption itself, while the semi-public charging case is characterized by a load generated by a building. Consequently, the only electricity consumers at this location are the EVs, as there is no consumption of any building.

With regard to LLB, the EV owners would help in lowering the total electricity requested from the grid. Comparable to the semi-public charging case, the resulting benefits from avoided costs for grid electricity consumption should be allocated to the EV owner. At the same time, EV owner and LH are two separate entities and the allocation of obtained benefits would required detailed information about the duration of single charging sessions. Thus, this study does not reflect such benefits. At the same location, a CPO has rented a location, built solar panels, installed charging stations and operates a public charging hub. While the charging stations are provided and operated by a CPO, the MSP grants access to the stations itself.

The tariff for standard charging is set to $0.29 € / \mathrm{kWh}$. By performing LLB, the EV owner is offered a cheaper tariff as for standard charging, namely $0.23 € / \mathrm{kWh}$, because the discharged electricity of the EVs can be used by the CPO to balance loads. Furthermore, the tariff for public charging is lower compared to the semi-public charging case, as the utilization of the charging stations is more efficient. Again, the benefit for the EV owner is in form of saved consumption costs, as a lower tariff is applied compared to standard charging. This benefit is described as indirect compensation for V2G services.

As an alternative V2G service, the EV owner can also perform IS. Tariffs for IS are equal to the standard tariffs, but including higher costs for V2G charging stations. In this case, the tariff for IS is set to $0.39 € / \mathrm{kWh}$. Even though the EV owners will not experience any indirect compensation for IS in a public charging case, they will still profit from direct compensation for this service. Under the described circumstances, this benefit for imbalance service of the EV owner will be cut down by the profits of the CPO, the MSP and the LH. All payments and compensations in a public charging case are summarized in Figure 3. 


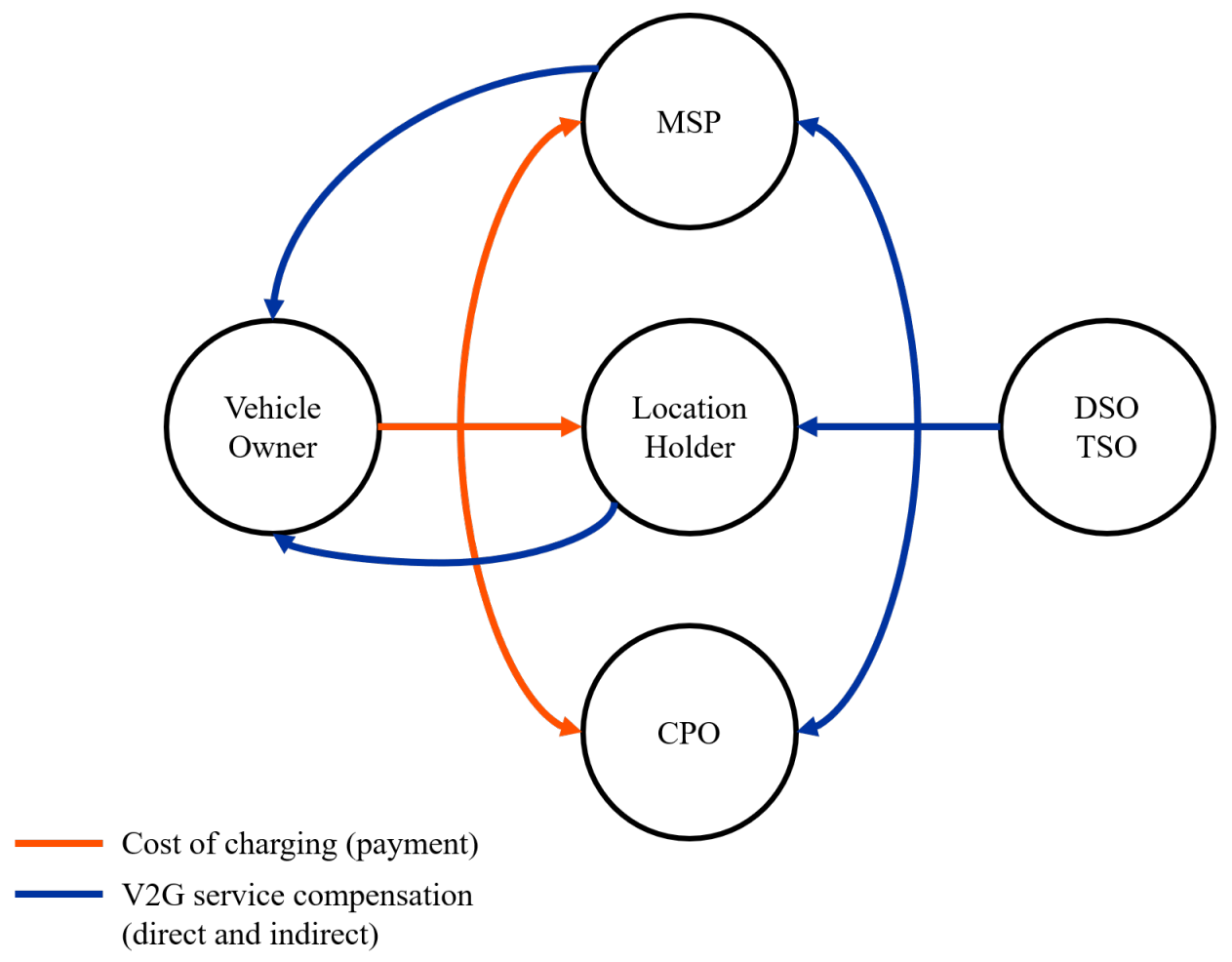

Figure 3. Definition of a public charging case (following [25], own compilation).

\subsubsection{Quantitative Description of the Charging Cases}

In Section 2.4.1, a general description of all charging locations is provided. This section further quantitatively describes the three different charging cases. For this study, three different charging cases could be distinguished for example by the following criteria: the size of the PV installation, the number of installed chargers, the electricity supplied by the grid, the electricity fed back to the grid and the electricity produced by the PV installation. For every possible charging location, the size of PV installations and the number of installed charging stations were selected. The supplied, injected and generated electricity is the output of our internal calculations performing energy balance with an energy cost minimization algorithm. Details about the different charging cases are gathered in Table 3.

Table 3. Charging location description of different charging cases (source: estimations/own compilation and output of internal calculations performing energy balance with an energy cost minimization algorithm).

\begin{tabular}{|c|c|c|c|c|c|c|c|}
\hline Charging Case & Type of Charging & PV Size kWp & Charger Size kW & Number of Chargers Amount & Grid Supply kWh/Year & Grid Injection kWh/year & PV Production kWh/Year \\
\hline Private & Standard & 3.8 & 22 & 1 & $11,123.00$ & -1599.00 & 4063.00 \\
\hline Private & LLB & 3.8 & 22 & 1 & $10,609.00$ & -1430.00 & 4063.00 \\
\hline Private & V2G & 3.8 & 22 & 1 & $11,123.00$ & -1599.00 & 4063.00 \\
\hline Semi-public & Standard & 12 & 22 & 12 & $229,715.00$ & -4282.00 & $60,763.85$ \\
\hline Semi-public & LLB & 12 & 22 & 12 & $228,910.00$ & -3919.00 & $60,763.85$ \\
\hline Semi-public & IS & 12 & 22 & 12 & $229,715.00$ & -4282.00 & $60,763.85$ \\
\hline Public & Standard & 12 & 22 & 12 & $11,896.37$ & $-55,898.77$ & $60,763.85$ \\
\hline Public & LLB & 12 & 22 & 12 & 3788.39 & $-48,299.16$ & $60,763.85$ \\
\hline Public & IS & 12 & 22 & 12 & $11,896.37$ & $-55,898.77$ & $60,763.85$ \\
\hline
\end{tabular}

In addition to the values provided in Table 4, the following costs were used in the internal calculations: 
Table 4. Characterization of different assets at the charging locations (n.a. = not applicable).

\begin{tabular}{ccccc}
\hline Asset & CAPEX & OPEX & Green Certificates & Lifetime \\
\hline PV installation & $1000.00 € / \mathrm{kWp}$ & $15.00 € / \mathrm{kWp} /$ year & $0.022 € / \mathrm{kWh}[35]$ & 15 years \\
Standard charger & $60.00 € / \mathrm{kW}[36]$ & n.a. & n.a. & 15 years \\
V2G charger & $115.00 € / \mathrm{kW}[24,36]$ & $5.00 \%$ p.a. [24] & n.a. & 15 years \\
\hline
\end{tabular}

Based on this information and with the Equations presented in Section 2.4, the tariffication schemes for the different charging cases and types in Table 5 are proposed.

Table 5. Tariffs for different charging cases ( $\mathrm{PM}=$ profit margin, $\mathrm{LH}=$ location holder, $\mathrm{CPO}=$ charge point Operator and MSP = mobility service provider, source: own compilation).

\begin{tabular}{cccccccc}
\hline $\begin{array}{c}\text { Charging } \\
\text { Case }\end{array}$ & $\begin{array}{c}\text { Type of } \\
\text { Charging }\end{array}$ & $\begin{array}{c}\text { Cost of } \\
\text { Electricity }\end{array}$ & $\begin{array}{c}\text { Marginal } \\
\text { Cost }\end{array}$ & $\begin{array}{c}\text { PM } \\
\text { LH }\end{array}$ & $\begin{array}{c}\text { PM } \\
\text { CPO }\end{array}$ & $\begin{array}{c}\text { PM } \\
\text { MSP }\end{array}$ & Tariff \\
\hline Unit & & $€ / \varnothing \mathrm{kWh}$ & $€ /$ extra kWh & $\%$ & $\%$ & $\%$ & $€ / \mathrm{kWh}$ \\
Private & Standard & 0.22 & n.a. & n.a. & n.a. & n.a. & 0.22 \\
Private & V2G-LLB & 0.22 & n.a. & n.a. & n.a. & n.a. & 0.22 \\
Private & V2G-IS & 0.23 & n.a. & n.a. & n.a. & n.a. & 0.23 \\
Semi-public & Standard & 0.12 & 0.23 & 10 & n.a. & 10 & 0.28 \\
Semi-public & V2G-LLB & 0.12 & 0.28 & 10 & n.a. & 10 & 0.34 \\
Semi-public & V2G-IS & 0.12 & 0.29 & 10 & n.a. & 10 & 0.35 \\
Public & Standard & 0.24 & n.a. & 10 & 10 & 10 & 0.31 \\
Public & V2G-LLB & 0.18 & n.a. & 10 & 10 & 10 & 0.23 \\
Public & V2G-IS & 0.30 & n.a. & 10 & 10 & 10 & 0.39 \\
\hline
\end{tabular}

A first observation concerns the range of the presented tariffs. In a private charging case, the calculated tariffs for standard, LLB and IS charging of $0.22,0.22$ and $0.23 € / \mathrm{kWh}$ built on the presented assumptions would be lower than the average household electricity price of Belgium of $0.24 € / \mathrm{kWh}$ [26].

\subsection{General Assumptions}

In particular, the TCO is calculated for a vehicle that is bought and operated in Flanders. Therefore, the assumptions of this study were collected for Flanders, or if not available for this geographic region, for Belgium and the European Union. All underlying values are gathered in Table 6 [37-40].

Table 6. Overview of the general assumptions [37-40].

\begin{tabular}{cccc}
\hline No. & Assumption & Value & Unit \\
\hline 1 & $\varnothing$ age of vehicle fleet in & 9.23 & years \\
2 & Belgium [37] & 14.483 & $\mathrm{~km} /$ year \\
3 & Travelled vehicle kilometres [38] & km \\
& Lifetime vehicle kilometres & 133.678 & $\%$ p.a. \\
4 & (assumption 1 $\times$ assumption 2) & -0.39 & USD/EUR \\
5 & Real discount rate [39] & 0.83 & \\
\hline
\end{tabular}

\subsection{Costs at Purchase Time}

A major contributor to the costs at the purchase time are the purchase prices of the vehicles themselves. In this study, four EVs were selected due to the availability as an object of study within the research group. These vehicles are a Nissan Leaf Acenta MY 19, a Renault Zoe R110, a Hyundai Kona Electric Sky and a BMW i3 (120 Ah). All vehicles were selected without any extra vehicle options, and their purchase prices can be found in Table 3 [41-44]. Currently, there are no subsidies in place for purchasing EVs, but EVs are exempted from the registration tax in Flanders region [45]. In addition to the purchase 
price, EV owners also have to install a charging station, which can be obtained for about for about $€ 1319.00[36]$.

\subsection{Operational Costs}

The electricity consumption provided by the vehicle manufacturers is multiplied with the annual travelled kilometre of 14.483 and a tariff charged for the consumed electricity. Values for the electricity consumption per vehicle are provided in Table 3. Tariffs are identified according to the three charging cases, namely a private, a semi-public and a public charging case. The tariffs for standard charging are $0.22 € / \mathrm{kWh}, 0.25 € / \mathrm{kWh}$ and $0.29 € / \mathrm{kWh}$ in a private, semi-public and a public charging case, respectively.

\subsection{Non-Operational Costs}

In this study, the first years of ownership are covered by an omnium insurance, and, from the fourth year onwards, a civil liability insurance was chosen. Insurance premiums were derived from AXA vehicle insurance [46] and can be found in Table 3. In addition, small maintenance will be completed after driving $10,000 \mathrm{~km}$ and large maintenance will be due after driving 30,000 $\mathrm{km}$ [12]. In addition to maintenance costs, tire replacements are required after driving 40,000 $\mathrm{km}$ [12]. For the replacement service and balancing, costs of $€ 56.00$ are assumed [12].

Prices for new tires are derived from either the manufacturer's, Michelin or QTeam, website and can be found in Table 3, including the aforementioned service charge [44,47,48]. Furthermore, the Flemish government levies an annual road tax for all vehicles but EVs are excluded from this tax [49]. When assessing the TCO of EVs, special attention should be given to the battery. Replacement costs of the traction battery can have a major impact on the TCO. However, EVs currently come along with a distance warranty of 160,000 km. As, during the ownership of an EV, the driven mileage of $133,678 \mathrm{~km}$ is below this distance warranty of the manufacturer, no replacement costs for the traction battery was taken into account. The EV specific and non EV specific costs are gathered in Tables 7 and 8.

Table 7. EV specific characteristics and costs [41-44,47,48].

\begin{tabular}{ccccccc}
\hline EV Type & Power & $\begin{array}{c}\text { Electricity } \\
\text { Consumption }\end{array}$ & $\begin{array}{c}\text { Purchase } \\
\text { Price Incl. VAT }\end{array}$ & Omnium & $\begin{array}{c}\text { Civil } \\
\text { Liability }\end{array}$ & $\begin{array}{c}\text { Tire } \\
\text { Replacement }\end{array}$ \\
\hline Nissan Leaf & $\mathrm{kW}(\mathrm{pk})$ & $\mathrm{kWh} / \mathrm{km}$ & $€$ & $€ /$ year & $€ /$ year & $€ /$ replacement \\
Renault Zoe & $80(108)$ & 0.171 & $36,540.00$ & 1269.77 & 320.38 & 462.84 \\
Hyundai Kona & $150(204)$ & 0.173 & $32,600.00$ & 1107.37 & 297.15 & 411.44 \\
BMW i3 & $125(170)$ & 0.154 & $49,999.00$ & 1309.43 & 309.72 & 754.88 \\
\hline
\end{tabular}

Table 8. Overview of non-EV specific costs [14,50].

\begin{tabular}{ccccc}
\hline \multirow{2}{*}{ Cost Type } & $\begin{array}{c}\text { Small } \\
\text { Maintenance [14] }\end{array}$ & $\begin{array}{c}\text { Large } \\
\text { Maintenance [14] }\end{array}$ & $\begin{array}{c}\text { Fines } \\
\text { \& Parking [14] }\end{array}$ & $\begin{array}{c}\text { Technical } \\
\text { Control [50] }\end{array}$ \\
\hline Unit & $€ /$ maintenance & $€ /$ maintenance & $€ /$ year & $€ /$ year \\
Amount & 64.35 & 109.85 & 83.98 & 32.70 \\
\hline
\end{tabular}

\section{Results}

\subsection{TCO Results}

Overall, the TCO without V2G service is found to range from $€ 41,569.96$ for a Renault Zoe charged at a private charging location up to $€ 61,225.54$ of a Hyundai Kona charged at a public charging case. A primary observation of the TCO results is that some costs included in the TCO remain the same regardless of the charging case. These costs are the purchase price, costs for insurance, maintenance costs and costs for fines and parking.

While the costs for fines and parking are almost negligible (1-2\% of the TCO for all EVs), the sum of purchase costs, insurance premiums and maintenance costs make up more 
than $80 \%$ of the TCO of each vehicle among all charging cases. On the other hand, the TCO contains costs that vary when applied in different charging cases, namely consumption costs. The consumption costs make up $7 \%$ of the TCO of a BMW i3, specifically $€ 3931.51$ when charged at home and can rise to $17 \%$ of the TCO of a Renault Zoe, in particular $€ 7316.00$ when charged at a public charging station. Logically, the consumption cost rises with the increase of the tariffs.

Therefore, the consumption costs are cheapest when the EVs are charged at home with a tariff of $0.22 € / \mathrm{kWh}$ and highest in a public charging case, where a tariff of $0.31 € / \mathrm{kWh}$ is charged. Lowest TCO per $\mathrm{km}$ of $€ 0.31, € 0.32$ and $€ 0.33$ were identified for the Renault Zoe, followed by TCO per km of $€ 0.37, € 0.38$ and $€ 0.38$ for the Nissan Leaf, respectively, in a private, semi-public and public charging case. The TCO per $\mathrm{km}$ for the BMW i3 were calculated to be $€ 0.40, € 0.40$ and $€ 0.41$, while highest TCO per $\mathrm{km}$ of $€ 0.44, € 0.45$ and $€ 0.46$ were determined for the Hyundai Kona in, respectively, a private, semi-public and public charging case.

All results are visualized in Figures $4-6$ and TCO calculations are provided in Table 9. The TCO conducted by [14] follows a similar approach to calculate TCO. As a result, $€ 0.25$, $€ 0.31$ and $0.66 € / \mathrm{km}$ were identified as TCO for electric vehicles in a city car, a medium car and a premium car segment and are depicted in different dotted lines (see Figures 4-6) [14]. In contrast to the determined TCO of EVs, TCO per km of petrol cars remain with $€ 0.18$, $€ 0.25$ and $€ 0.61$ for, respectively, a city, a medium and a premium car segment still below [14].

Table 9. TCO without V2G impacts of different charging cases (source: own compilation).

\begin{tabular}{ccccc}
\hline EV Type & Unit & Private & Semi-Public & Public \\
\hline Nissan Leaf Acenta MY 19 & $€$ & $48,893.47$ & $50,293.10$ & $50,992.91$ \\
Renault Zoe R110 & $€$ & $41,569.96$ & $42,985.96$ & $43,693.96$ \\
Hyundai Kona Sky & $€$ & $59,334.82$ & $60,595.30$ & $61,225.54$ \\
BMW i3 (120 Ah) & $€$ & $53,011.81$ & $54,084.04$ & $54,620.16$ \\
\hline
\end{tabular}

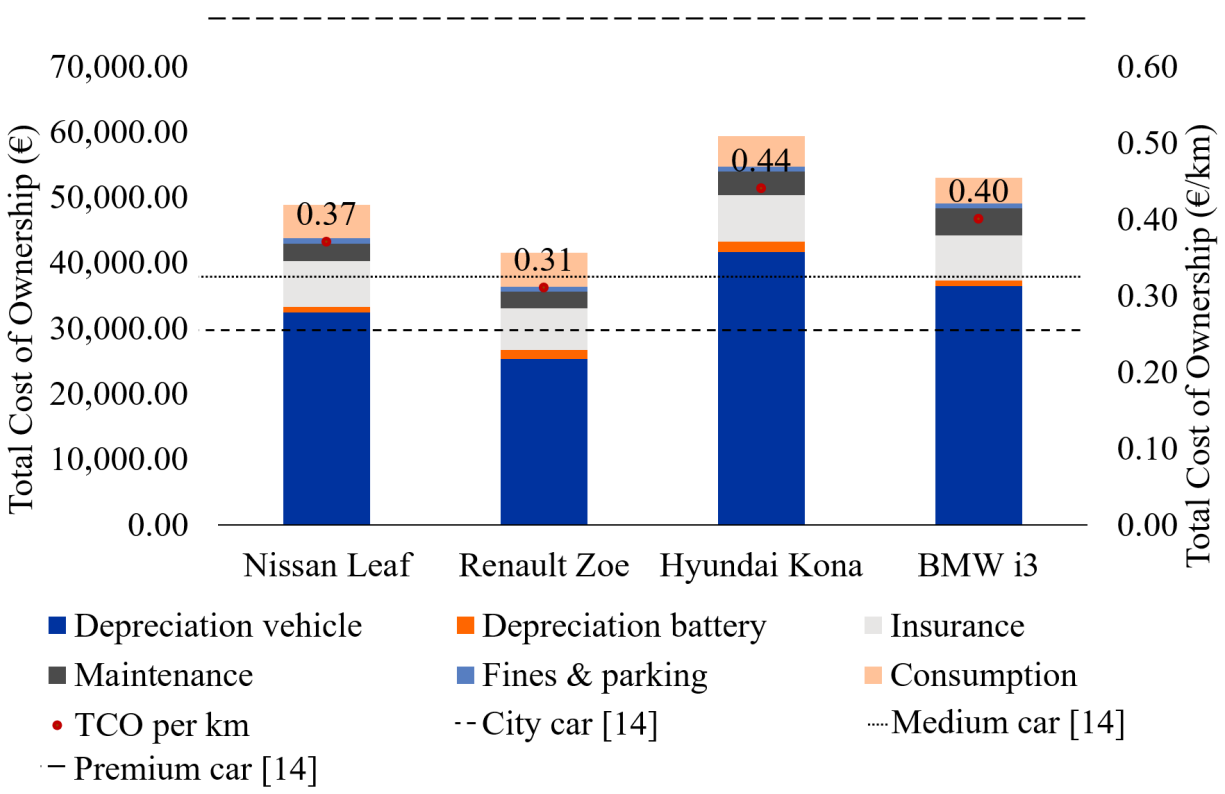

Figure 4. Standard TCO in a private charging case (source: own compilation). 


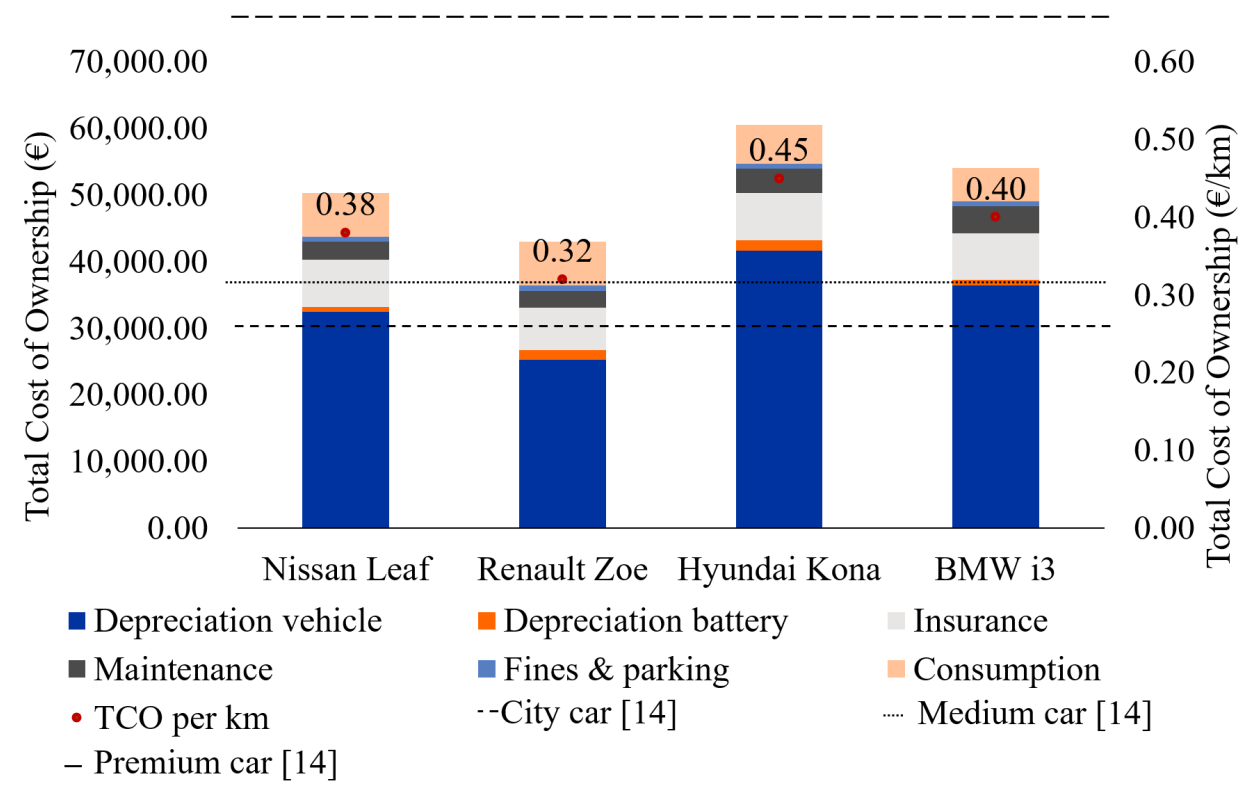

Figure 5. Standard TCO in a semi-public charging case (source: own compilation).

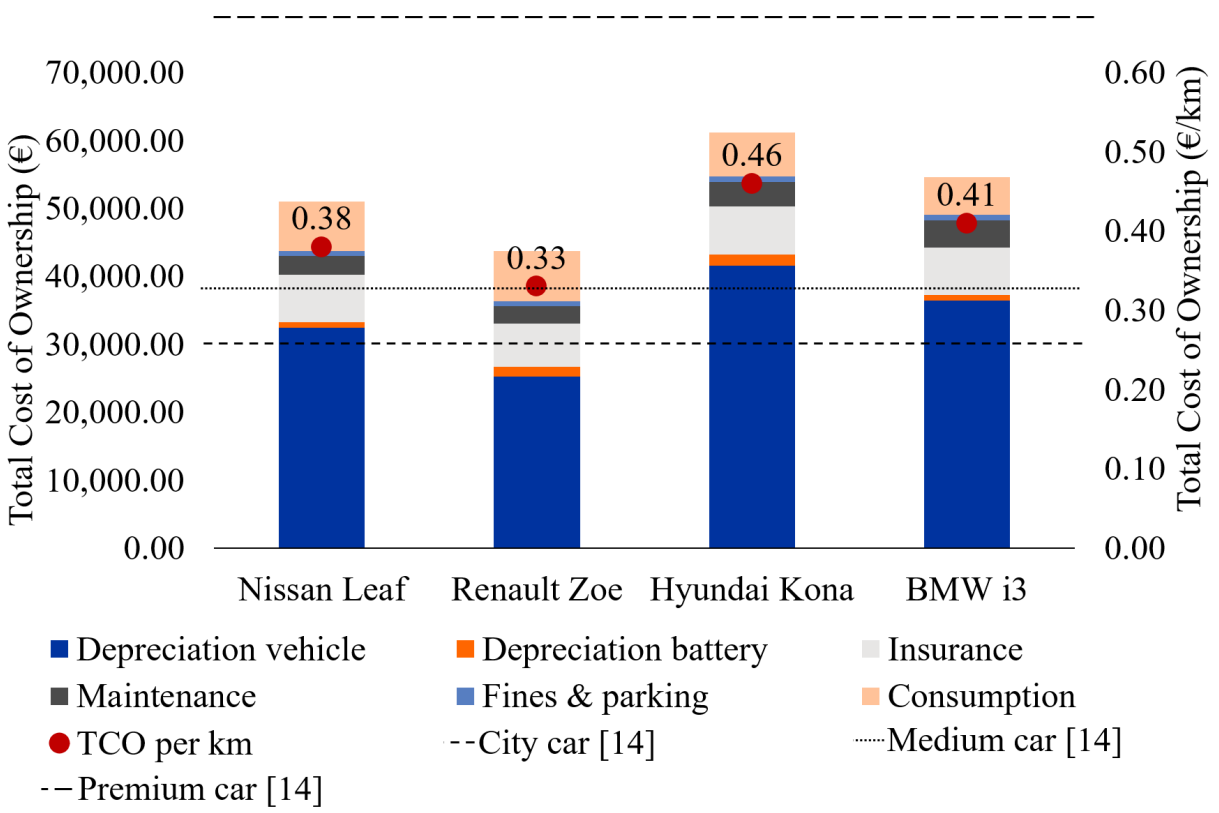

Figure 6. Standard TCO in a public charging case (source: own compilation).

As the aim of this study is to understand the impact of V2G services on the TCO of EVs, special attention should be given to the cost components that are not determined externally but can be influenced. Such influenceable cost components would be, for example, the consumption costs. Already by defining identifying different tariffs for various charging cases showed that the TCO could variate. In this study, the consumption costs make up between $7 \%$ and $17 \%$ of the TCO. Therefore, this range proposes the possibility to influence the TCO by modification of the tariffs. In addition to of the consumption costs, the purchase price is still one of the main cost contributor. To stimulate the mass implementation of EVs providing V2G services, the purchase prices could be directly decreased by offering subsidies for EVs participating in V2G technology or any other political intervention. 


\subsection{V2G TCO Results}

Vehicle-to-Grid impacts for LLB range from $€-1793.60$ for the Renault Zoe, charged at a public charging station up to $€ 1321.60$ for the Renault Zoe, charged at a semi-public charging case. When LLB is performed at public charging stations, the V2G decrease on the TCO was found to be highest, whereas an increase was observed when EVs use semi-public charging stations.

In a public charging case, the TCO decrease results from indirect compensation. The tariffs for LLB are already below the standard tariff, and thus the price difference results in an decrease in the public charging cases. As a result, highest compensation of $€-1793.60$ is given for a Renault Zoe charged at public charging cases. Unfortunately, this is not the case in a semi-public charging case; here, the indirect compensation is an incline of the consumption costs compared to standard charging. When comparing the tariffs for standard and LLB charging at semi-public charging cases, the tariff for providing LLB is $€ 0.06 / \mathrm{kWh}$ higher than for standard charging, even though the EV owner offers its unused electricity.

Due to the low utilization of the charging stations in the semi-public charging case, overall the V2G TCO ends up with an increase. V2G costs when providing LLB occurs only in the private charging case and accounts for $€ 155.05$ over the EVs lifetime. All other V2G costs, such as V2G chargers and its maintenance are already covered by the charged tariffs. In addition to potential indirect compensation, in the case of LLB EV owners can also obtain benefits in form of avoided costs for grid electricity consumption. In this study, we assumed that this benefit can only be obtained at private charging cases.

In Table 10, the potential benefits over an EV lifetime are presented and range from $€-69.38$ in a semi-public charging case to $€ 1452.58$ at a public charging case, while the benefits of saved electricity costs are $€-387.63$ at private charging stations.

Contrary to providing LLB, the EV owner can have a different V2G impact on the TCO when providing IS. With a total of $€-11,076.81$ in the private charging case, both the Nissan Leaf and the BMW i3 obtain highest direct compensation from IS, while least direct compensation is received by the Renault Zoe and the Hyundai Kona in a public charging case, namely $€-7687.83$. In the case of private charging, V2G costs of $€ 4430.72$ are identified for the Nissan Leaf and the BMW i3. For the Renault Zoe and the Hyundai Kona, lower V2G costs are determined, precisely $€ 4393.05$. Next to direct compensation, indirect compensation due to the tariff differences had a diminishing effect on the V2G TCO.

A maximum indirect compensation of $€-3634.40$ was achieved when the Renault Zoe is charged at public charging stations, while the minimum indirect compensation of $€-2287.43$ was obtained by the BMW i3 plugged in at public charging stations. In terms of TCO per $\mathrm{km}$, smallest prices of $€ 0.24, € 0.23$ and $€ 0.24$ were obtained for the Renault Zoe, followed by TCO per $\mathrm{km}$ of $€ 0.29, € 0.29$ and $€ 0.30$ for the Nissan Leaf, in, respectively, a private, semi-public and public charging case. Higher TCO per $\mathrm{km}$ of $€ 0.33, € 0.32$ and $€ 0.33$ are obtained for the BMW i3 and highest TCO per $\mathrm{km}$ are $€ 0.37, € 0.37$ and $€ 0.38$ evaluated for the Hyundai Kona in, respectively, a private, a semi-public and a public charging case.

Table 10. Self-consumption of PV-generated electricity of different charging cases (source: own compilation).

\begin{tabular}{ccccc}
\hline Parameter & Unit & Private & Semi-Public & Public \\
\hline PV production & $\mathrm{kWh} /$ year & 4063.00 & $60,763.85$ & $60,763.85$ \\
Standard charging & $\%$ & 60.64 & 92.95 & 8.01 \\
V2G charging & $\%$ & 64.80 & 93.55 & 20.51 \\
Consumption increase & $\%$ & 4.16 & 0.60 & 12.51 \\
Avoided grid electricity & $\mathrm{kWh} /$ year & 169.00 & 30.25 & 633.30 \\
Obtained benefit & $€ /$ year & 40.56 & 7.26 & 151.99 \\
Discounted benefit & $€ /$ lifetime & -387.63 & -69.38 & -1452.58 \\
\hline
\end{tabular}


In a similar study, the TCO for different vehicle segments were determined [13]. In that study, a private charging case was reflected and estimated V2G benefits of about $€ 900.00$ over the EV lifetime [13]. The TCO per $\mathrm{km}$ of the previously mentioned study were estimated to be $€ 0.27, € 0.35$ and $€ 0.73$ for an electric vehicle of the city car, the medium car and the premium car segments [13]. In Figures 4-6, the TCO per $\mathrm{km}$ are reflected in yellow for the city car segment, in light green for the medium car segment and in light blue for the premium car segment. Combining the TCO results of Table 10 with the V2G impact of Table 11 reveals the TCO for EV owners participating in a V2G system. Exemplary, the standard TCO and V2G TCO are presented for the Nissan Leaf only while the Appendix A covers the Figures of the other vehicles. The V2G TCO results are summarized in Figures 7-12 exemplary for the Nissan Leaf only and Figures A1-A18 covers the V2G TCO of the other vehicles. All V2G impacts can be found in Table 11.

Table 11. V2G impact in EURO of different charging cases (source: own compilation).

\begin{tabular}{cccccc}
\hline EV Type & V2G & Unit & Private & Semi-Public & Public \\
\hline Nissan Leaf Acenta MY 19 & LLB & $€$ & -232.58 & 1959.48 & -1213.01 \\
Nissan Leaf Acenta MY 19 & IS & $€$ & -9631.96 & $-11,492.75$ & $-10,786.30$ \\
Renault Zoe R110 & LLB & $€$ & -232.58 & 1982.40 & -1227.20 \\
Renault Zoe R110 & IS & $€$ & -9610.37 & $-11,448.17$ & $-10,755.83$ \\
Hyundai Kona Sky & LLB & $€$ & -232.58 & 1764.68 & -1092.42 \\
Hyundai Kona Sky & IS & $€$ & -9278.61 & $-11,155.81$ & $-10,418.89$ \\
BMW i3 (120 Ah) & LLB & $€$ & -232.58 & 1501.12 & -929.27 \\
BMW i3 (120 Ah) & IS & $€$ & -8933.51 & $-10,877.24$ & $-10,076.93$ \\
\hline
\end{tabular}

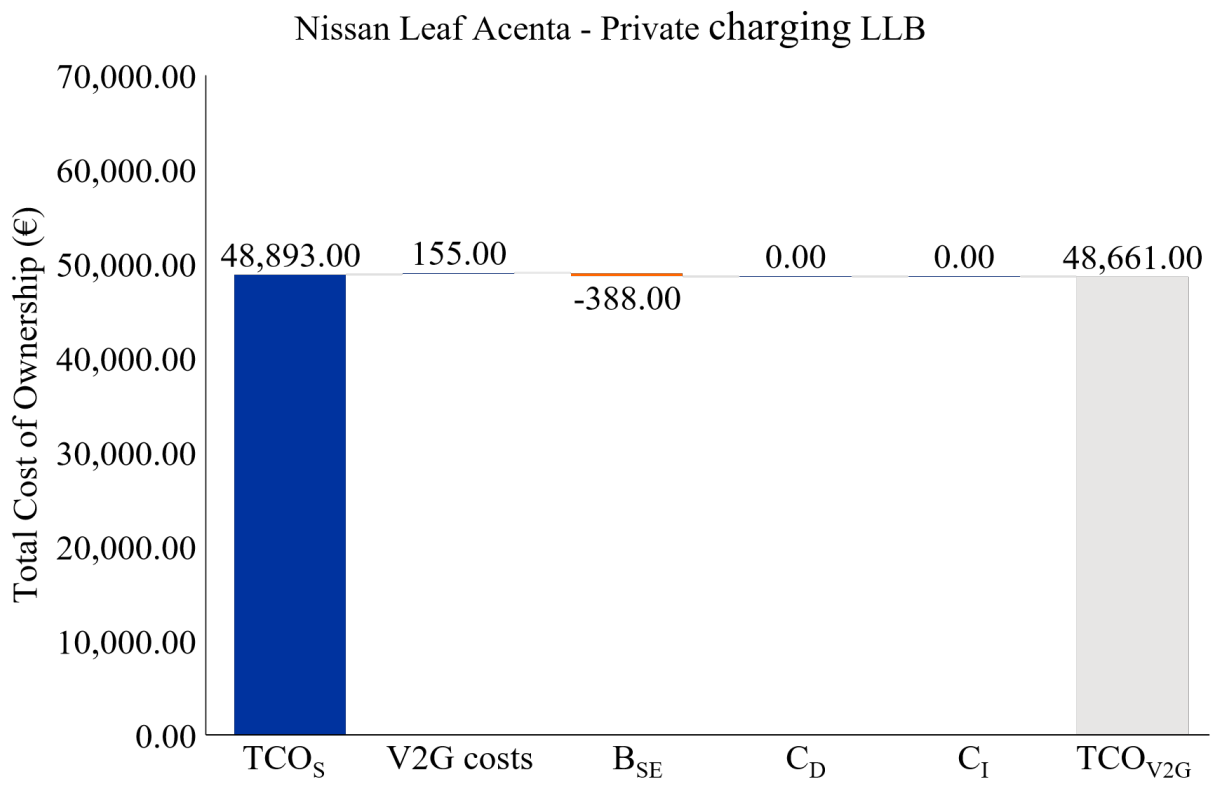

Figure 7. Standard and V2G TCO of a Nissan Leaf charged at a private charging case providing LLB $\left(T C O_{S}=\right.$ Standard TCO, $B_{S E}=$ benefit of saved electricity costs from the grid, $C_{D}=$ direct compensation, $C_{I}=$ indirect compensation, $T C O_{V 2 G}=V 2 G$ TCO; source: own compilation.) 


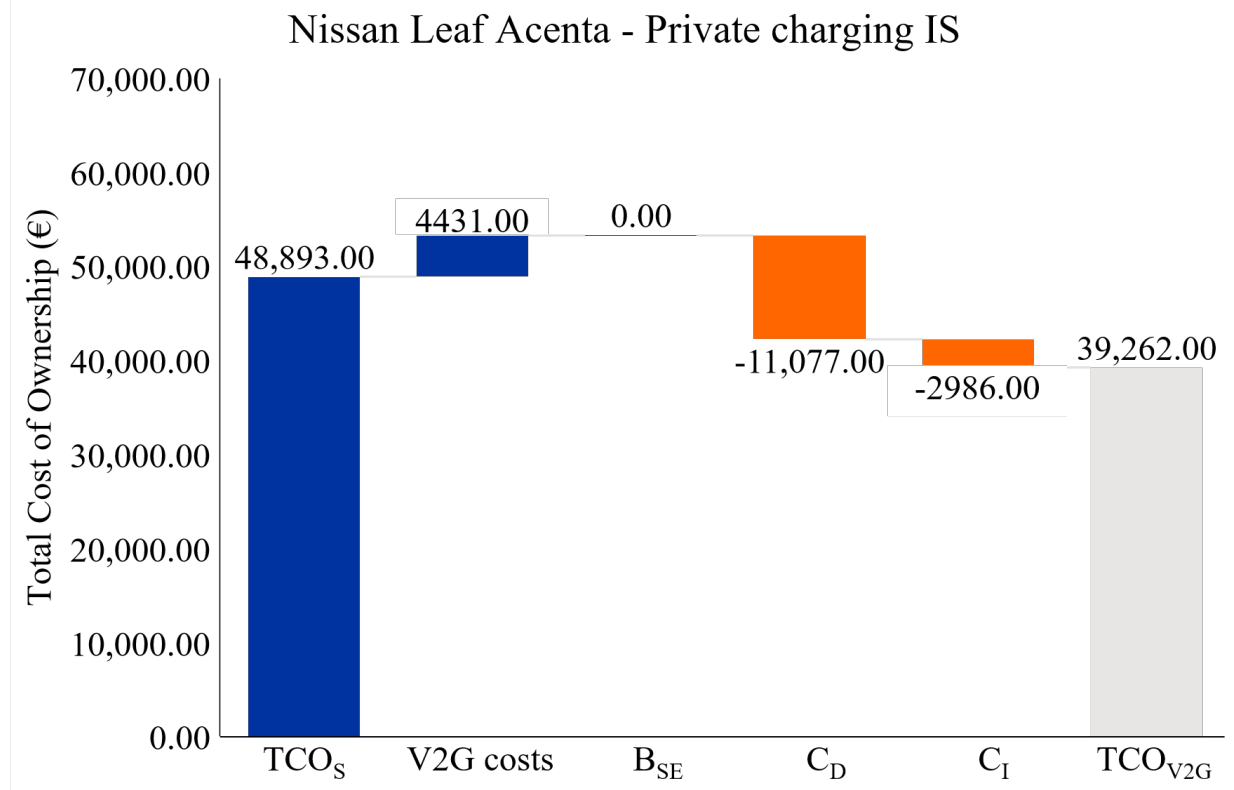

Figure 8. Standard and V2G TCO of a Nissan Leaf in a private charging case providing IS $\left(T_{C O}=\right.$ Standard TCO, $B_{S E}=$ benefit of saved electricity costs from the grid, $C_{D}=$ direct compensation, $C_{I}=$ indirect compensation, $T C O_{V 2 G}=V 2 G$ TCO); source: own compilation.)

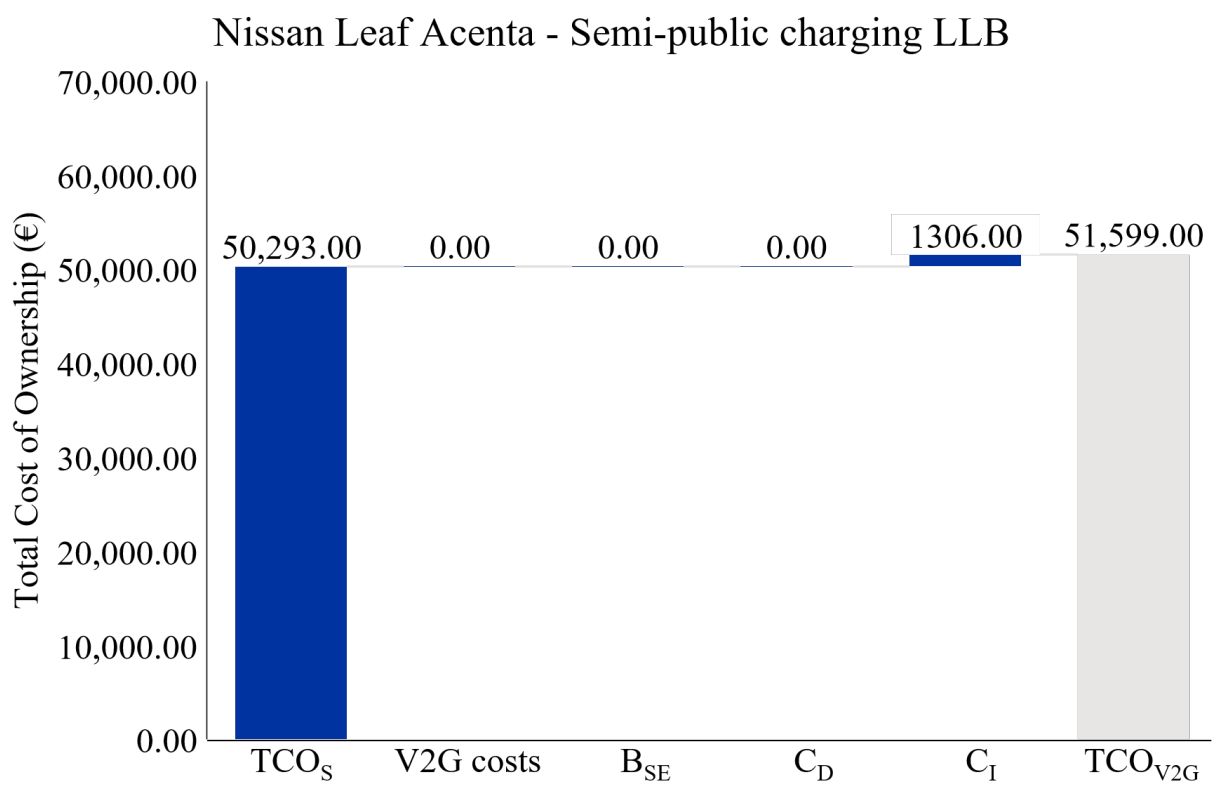

Figure 9. Standard and V2G TCO of a Nissan Leaf charged at a semi-public charging station providing $\mathrm{LLB}\left(T C \mathrm{TO}_{S}=\right.$ Standard TCO, $B_{S E}=$ benefit of saved electricity costs from the grid, $C_{D}=$ direct compensation, $C_{I}=$ indirect compensation, $T C O_{V 2 G}=V 2 G \mathrm{TCO}$ ); source: own compilation). 


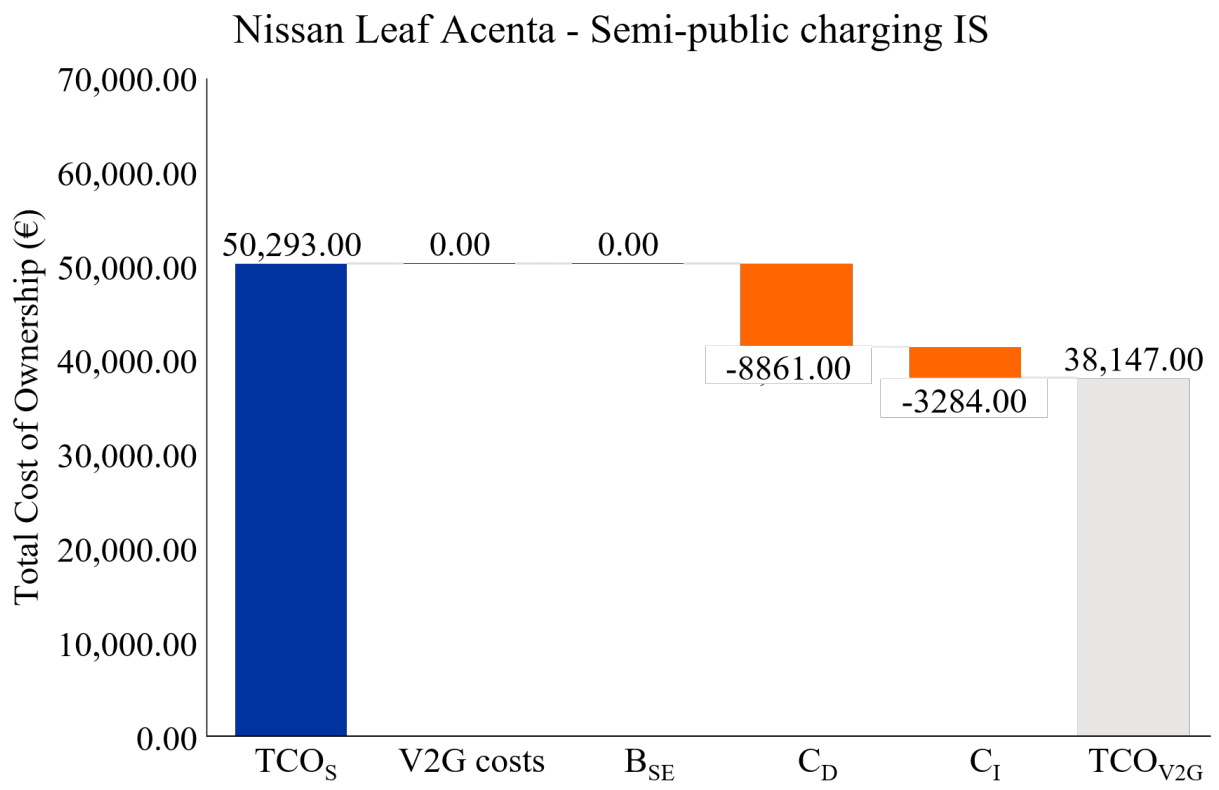

Figure 10. Standard and V2G TCO of a Nissan Leaf in a semi-public charging case providing IS $\left(\mathrm{TCO}_{S}=\right.$ Standard TCO, $B_{S E}=$ benefit of saved electricity costs from the grid, $C_{D}=$ direct compensation, $C_{I}=$ indirect compensation, $T C O_{V 2 G}=V 2 G$ TCO); source: own compilation).

Nissan Leaf Acenta - Public charging LLB

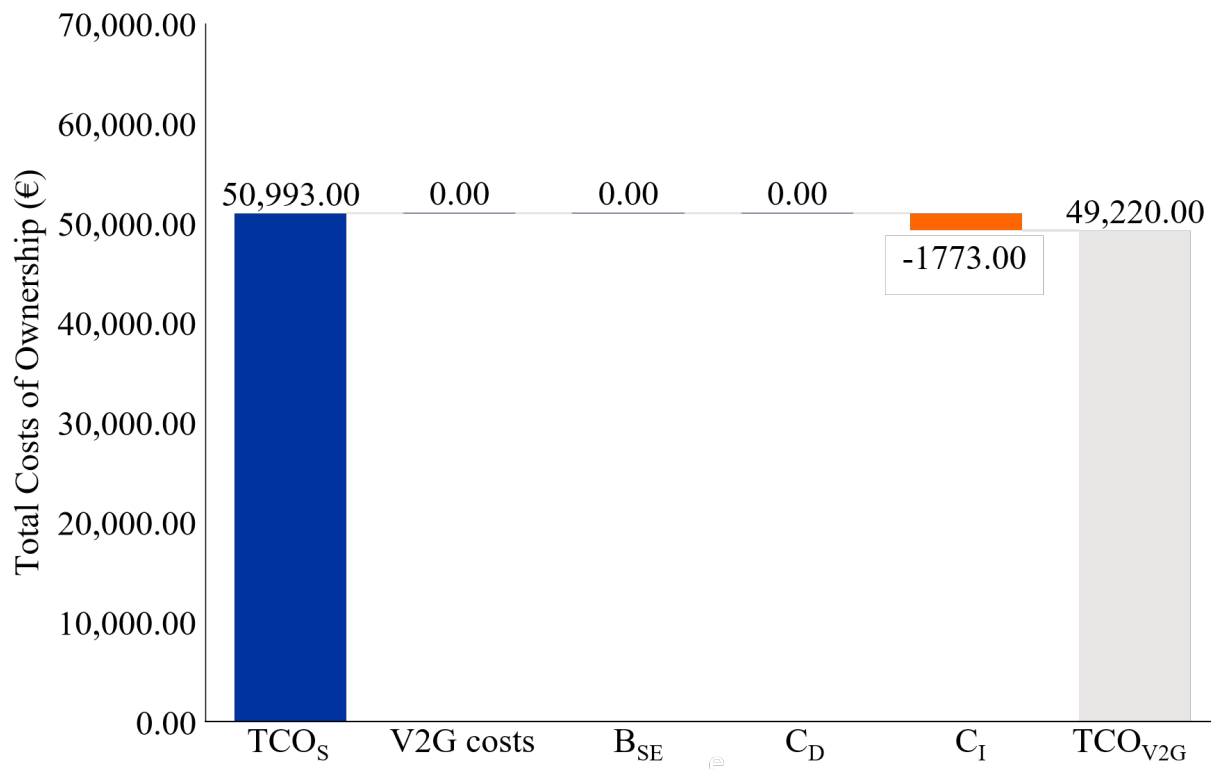

Figure 11. Standard and V2G TCO of a Nissan Leaf in a public charging case providing LLB $\left(\mathrm{TCO}_{S}=\right.$ Standard TCO, $B_{S E}=$ benefit of saved electricity costs from the grid, $C_{D}=$ direct compensation, $C_{I}=$ indirect compensation, $T C O_{V 2 G}=V 2 G$ TCO); source: own compilation). 


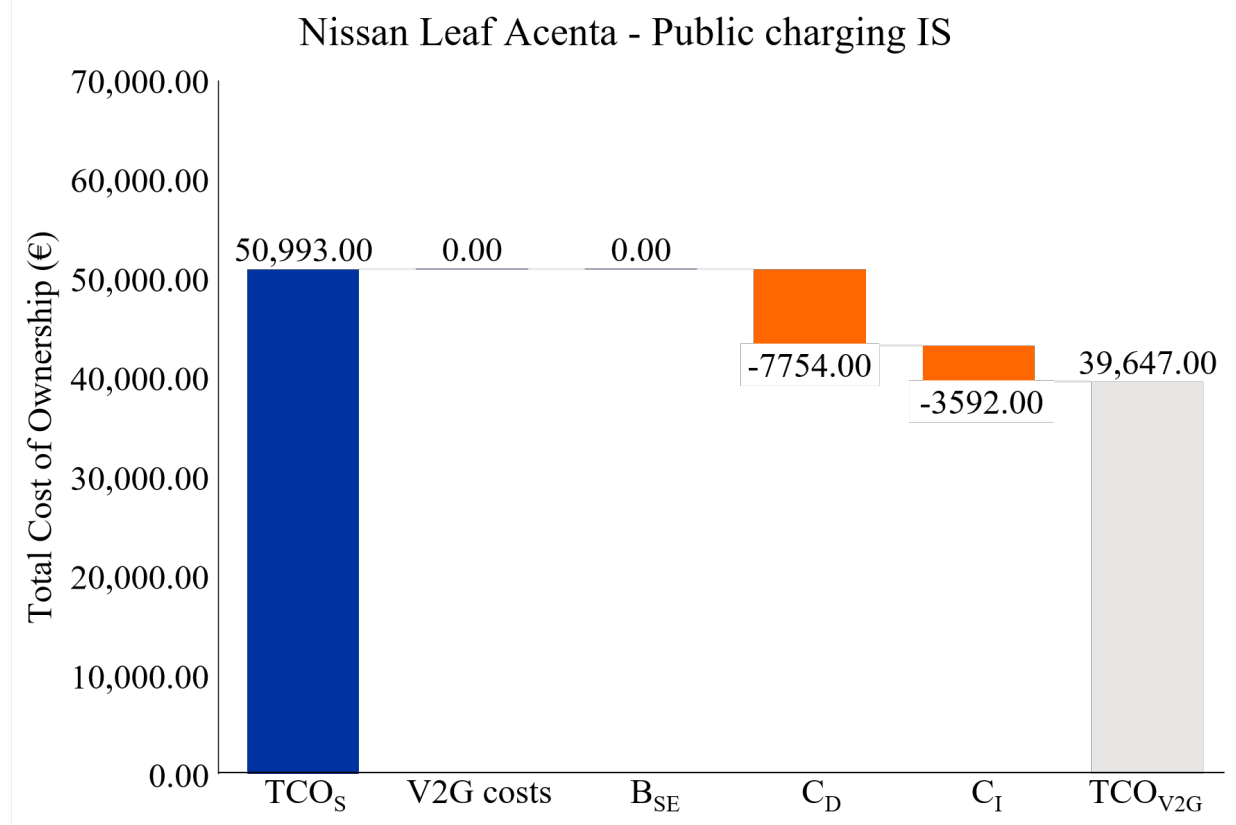

Figure 12. Standard and V2G TCO of a Nissan Leaf in a public charging case providing IS $\left(\mathrm{TCO}_{S}=\right.$ Standard TCO, $B_{S E}=$ benefit of saved electricity costs from the grid, $C_{D}=$ direct compensation, $C_{I}=$ indirect compensation, $T C O_{V 2 G}=$ V2G TCO); source: own compilation).

Under the described circumstances, overall, the V2G impacts from IS were greater than the LLB. When analysing IS impacts, two things need to be taken into account: (i) the direct compensation for IS over the EV lifetime is estimated comparably high and (ii) indirect compensation has only a limited effect on the TCO. The indirect compensation for IS is driven by the tariffs of the different charging stations. For every charging case, the tariff charged when providing IS is highest than for standard charging or LLB. Consequently, the electricity consumption costs should be highest for IS. However, due to the assumption that the EV owner will only bear $40 \%$ of the consumption costs as the rest of the consumption is covered when providing IS, the indirect compensation from IS still results in an overall reduction, nonetheless higher tariffs are considered.

Even though there is no direct compensation for LLB service for the EV owners, indirect consumption in form of a lower tariff when providing LLB can help attracting more EV owners to V2G services. For public and private charging, a tariff lower than for standard charging can be offered. Thus, the EV owner is already given one financial reason for participating in V2G services. Unfortunately, the tariff offered to EV owners providing LLB is still higher than the tariff for standard charging. Under such circumstances, no EV owner is expected to participate in V2G when, at the end of the day, they will end up with higher costs than normal.

Even though benefits due to avoided costs from grid electricity might appear relatively low compared to the TCO, they might gain increasing importance, especially given the fact of the ongoing rise of energy costs in Europe. Additionally, a future price increase of the grid electricity might even further lead to an incline of the benefits from saved grid electricity. In addition to the financial aspects, LLB also offers other advantages. First, the LH in a private charging case with their own PV installation might be less reliant on grid electricity by increasing the consumption of their self-generated PV-electricity.

Thereby, the security of electric supply could be enhanced and simultaneously a decreased dependency on the development of the future electricity prices ensured. Second, by providing LLB, EVs can be used simultaneously as a mode of transport and at the same time as a stationary electricity storage device. Thus, in a private household this could eventually result in avoiding a proper stationary battery at the charging location. To that 
end, broadening the system boundaries to include also the charging location itself, would help for better understanding of these interactions.

Regarding V2G costs, the study shows that the magnitude of the outlined costs is not comparable with major costs considered for the TCO, like depreciation or insurance costs. Nevertheless as the presented V2G costs are very specific for this study, it can be expected that other results might differ but always be in the same range of magnitude. When it comes to the profit margin of involved stakeholders, it can be observed that a higher number of involved stakeholders is negatively correlated to TCO of EV owners. Thus, from a TCO perspective of EV owners, it is more profitable to decrease the number of involved stakeholders. These findings can be extremely valuable for developing future business models.

\section{Sensitivity Analysis}

Due to the fact that all modified variables show similar influences, varying only in magnitude amongst the different vehicles, only the maximum and minimum impacts will be mentioned. For the same reason, relative changes of different sensitivities on the TCO of the Nissan Leaf are included (see Figure 13). All modified parameters of the sensitivity analysis are provided in Table 12.

Table 12. Changed parameter used for sensitivity analysis (source: own compilation).

\begin{tabular}{cccc}
\hline Sensitivity & Variable & Value & Unit \\
\hline Sensitivity 1.1 & Annual mileage & 10,000 & $\mathrm{~km}$ \\
Sensitivity 1.2 & Annual mileage & 20,000 & $\mathrm{~km}$ \\
Sensitivity 2.1 & Ownership time & 5 & years \\
Sensitivity 2.2 & Ownership time & 15 & years \\
Sensitivity 3 & Cost of V2G chargers & 4900.00 & $€$ \\
Sensitivity 4.1 & Provision for energy manager & 20 & $\%$ \\
Sensitivity 4.2 & Provision for energy manager & 50 & $\%$ \\
Sensitivity 5.1 & Profit margin & 5 & $\%$ \\
Sensitivity 5.2 & Profit margin & 15 & $\%$ \\
Sensitivity 6 & Charged electricity for IS service & 75 & $\%$ \\
Sensitivity 7 & Increased PV-selfconsumption & 90 & $\%$ \\
\hline
\end{tabular}

In sensitivity 1.1 and 1.2, the driven mileage over the ownership time is limited to $10,000 \mathrm{~km}$ and raised up to 20,000 km per year. The limitation results in a decrease of up to $6 \%$ while the raise leads up to $7 \%$ higher TCO. In Sensitivity 2.1 and 2.2, the investigated ownership duration of nine years, two months and 26 days is changed to 5 years and 15 years. By reducing the years of ownership to five, a maximum of $11 \%$ reduction of TCO can be linked with the saved consumption costs due to four years, two months and 26 days where the $\mathrm{EV}$ is not driven.

On the other hand, extending the years of ownership will not only raise consumption costs due to more driven kilometres. Additionally, in sensitivity 2.2, a battery replacement is considered. For the replacement, a future battery price of $89.00 € / \mathrm{kWh}$ is used [51]. While the years of ownership are extended to 15 years, the battery lifetime remains equal to nine years, two months and 26 days. Hence, after nine years, two months and 26 days, the battery will be replaced with a new one. Thus, the extension of the years of ownership increased the TCO up to $36 \%$. The third sensitivity discusses a change in the tariffs.

As the tariffs in this study compose of the investment costs for the energy generating assets and the charging station, sensitivity three represents a raise of the charging station costs from $€ 2564.00$ up to $€ 4900.00$. Therefore, the tariff for the private, the semi-public and the public charging case mount up to $0.23 € / \mathrm{kWh}, 0.49 € / \mathrm{kWh}$ and $0.40 € / \mathrm{kWh}$ when performing LLB, while the adjusted tariff when providing IS are $€ 0.24, € 0.49$ and $€ 0.53$, respectively.

For the standard charging case, the tariffs remain unaffected by the increase of the costs for the V2G charging stations. In the case of private charging, the impact is negligible, 
while in the semi-public and public charging case the change of the tariff increased the V2G TCO up to $9 \%$. Sensitivity four varies the V2G costs for the energy manager from $40 \%$ to $20 \%$ and $50 \%$. As described earlier, such costs would only be reflected in the private charging case. The decrease of these costs results in a maximum of $7 \%$ of the TCO in the case of IS, while increasing the costs would lead to an increase of a maximum of $3 \%$.

In sensitivity 5 , the PM of different stakeholders are assessed. Overall, the modification showed only very limited impact on the TCO (change of a maximum of $\pm 1 \%$ ). Sensitivity six presents an increase of $75 \%$ of the base case electricity costs when IS is provided instead of $40 \%$. Thereby, V2G TCO results can increase up to $10 \%$. In sensitivity 7 , the selfconsumption rate at private charging cases is changed from $65 \%$ up to $90 \%$.

The impact of increased self-consumption on the TCO is rather small, namely a maximum of $2 \%$ is observed in a private charging case. Considering all different sensitivities, the TCO results are found to be much more sensitive to the driven mileage, the years of ownership and the tariff than to any of the V2G impacts. The remaining sensitivities have only minor influence and are not further detailed (see Figures 13-15).

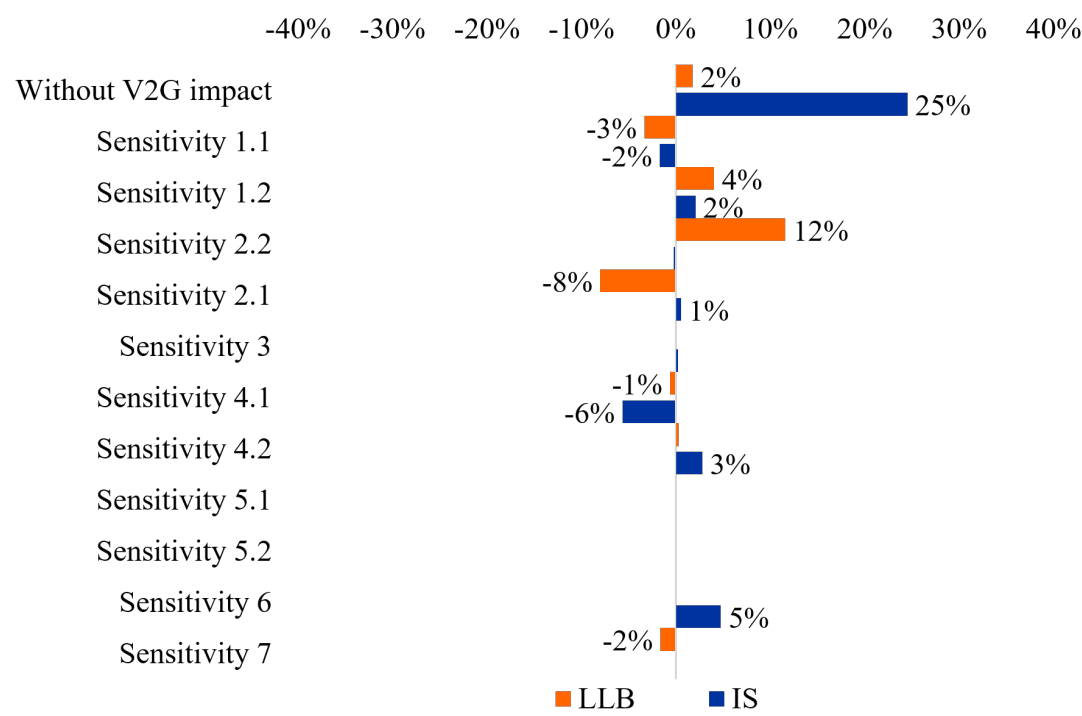

Figure 13. Relative change of V2G TCO for a Nissan Leaf in a private charging case (source: own compilation).

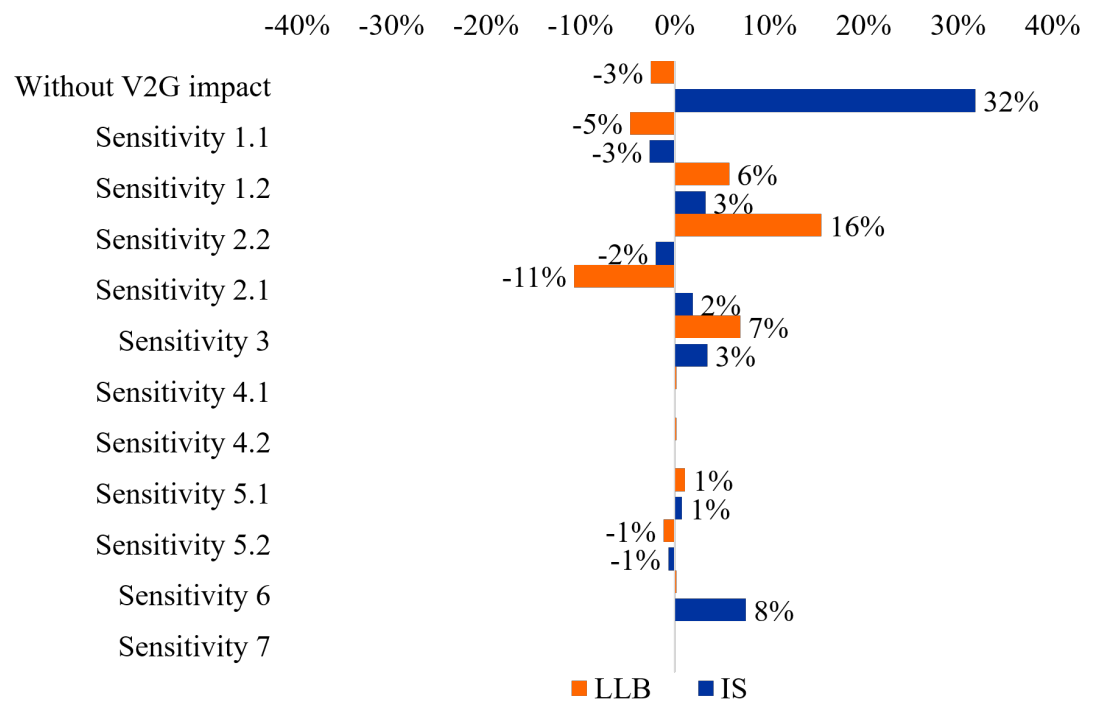

Figure 14. Relative change of V2G TCO for a Nissan Leaf in a semi-public charging case (source: own compilation). 


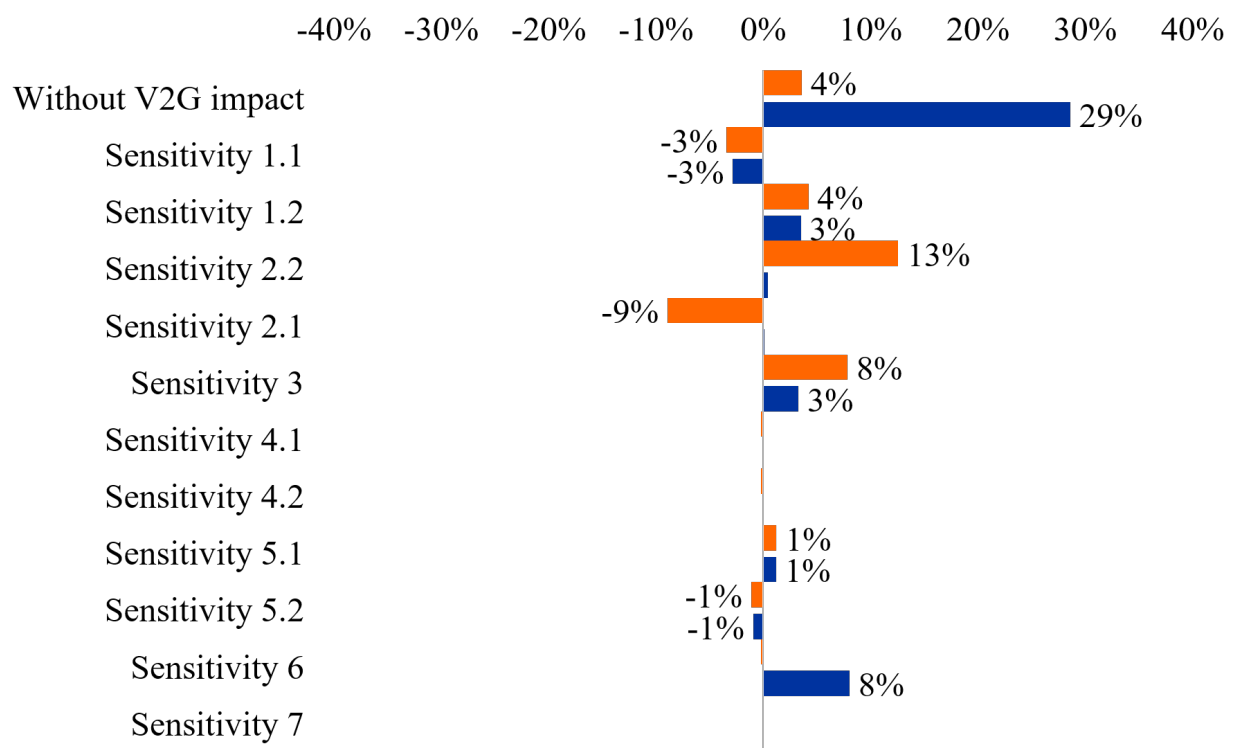

$\square$ LLB $\square$ IS

Figure 15. Relative change of V2G TCO for a Nissan Leaf in a public charging case (source: own compilation).

\section{Discussion}

First, to ensure that the obtained TCO results are representative, the same types of vehicles are normally accumulated to one vehicle segment (e.g., city, medium and premium car segment) $[12,14,15]$. Second, the human behaviour has an influence on charging the EVs $[14,15]$. These two limitations can be addressed by adjusting the research design of future TCO studies. Third, the study reflects only one type of V2G service at a time over the entire EV life. Fourth, revenues from IS are directly employed from [27]. Following [29], no degradation due to the V2G service was considered.

By proposing a comprehensive tariffication scheme, the coverage of more $\mathrm{V} 2 \mathrm{G}$ services at a time and a more realistic compensation for IS could be addressed. Furthermore, benefits due to increased self-consumption were calculated on average household electricity prices. However, a more appropriate calculation would reflect various electricity prices at peakand off-peak hours instead of applying only one static electricity price. Furthermore, financial compensation, transparent communication and reliable control of the system were found to be key drivers for EV owners to engage in V2G markets in the Netherlands [52].

As a consequence, future research can be expanded to better understand V2G from a holistic approach. Therefore, the following topics can be addressed: First, the motivation of the Belgian government and the legal requirements needed to bring this technology to the market should be understood. Second, the system boundaries of the study could contain also charging location to enhance understanding of technological synergies. Next, particular driving performance, battery degradation and other operational conditions tailored to the underlying V2G services could be investigated.

This holistic approach could even consider the end-of-life of the EVs. By exchanging the battery, for example, as considered in the sensitivity analysis, showed a primary increase of the TCO due to replacement costs. Thus, the EVs lifetime could be extended while the battery unusable for mobile application could further be used as a mobile storage before being dismantled and recycled. Extending the lifetime of the EV batteries could also help to keep goods longer in our economy and would be another step toward a more circular economy $[53,54]$.

In addition to the environmental benefits such end-of-life treatment could offer, it would, at the same time, also propose financial streams for the EV owners. This remains object to further research, whether all raised points could be integrated in the conven- 
tional TCO as presented in this article. One solution to better understand the interactions between single EVs and the charging location could be to reconsider the appropriateness of the conventional TCO methodology by for example conducting the TCO from a systematic approach.

\section{Conclusions}

In this study, a total cost of ownership calculation of four different electric vehicles was performed. These vehicles were studied in three different charging cases: (i) a private, (ii) a semi-public and (iii) a public charging case. In addition to standard charging, the vehicle owners can provide two different Vehicle-to-Grid services, namely local load balancing and imbalance service. Therefore, different tariffication schemes were elaborated based on internally developed algorithms. Three different Vehicle-to-Grid benefits and two cost types were determined to understand the Vehicle-to-Grid impacts on the total cost of ownership.

The defined charging cases can generally be described as locations where photovoltaic (PV) installations, vehicle charging stations and connections to the grid are established. The separate charging cases can be distinguished by the size of PV installation and number of installed chargers as well as by the accessibility toward the public. Depending on the accessibility, mobility service providers, charge point operators and transmission or distribution system operators are involved.

Overall, we observed that electric vehicle owners could have the lowest total cost of ownership in a semi-public charging case when providing imbalance service. This is a result of the direct compensation paid for the Vehicle-to-Grid service, the omitted costs for an energy manager and the reduced consumption costs due to participation in the imbalance market. When providing local load balancing, the vehicle owners would obtain the lowest total cost of ownership when charging at a private charging location due to the low tariff offered for charging.

Another finding of this study is that the total cost of ownership was always less when performing imbalance services than with local load balancing. This is due to the high direct compensation obtained for imbalance service. However, performing local load balancing might offer advantages other than a decrease of the total cost of ownership, e.g., a higher self-consumption of generated electricity from PV installations. Third, as the purchase costs for the Renault Zoe are the lowest amongst the four studied vehicles, it also demonstrated the lowest total cost of ownership. This is a logical consequence, as the purchase price still was found to be the major cost contributor to the total cost of ownership.

The conducted sensitivity analysis revealed that for the total cost of ownership variables, such as the driven mileage, the vehicle ownership in years and the applied tariffs, presented the highest influence. In contrast, the total costs of ownership were observed to be less sensitive to all Vehicle-to-Grid variables.

However, this study also faces certain limitations. The selected vehicles were not clustered into vehicle segments. Additionally, the human behaviour determining the charging location was not reflected in this study. Furthermore, no battery degradation was taken into account as the literature does not yet provide a clear perspective. Moreover, instead of peak- and off-peak prices reflecting different hours, only an average electricity price for calculation of benefits of self-consumption of PV generated electricity was considered. With regard to the Vehicle-to-Grid service, more limitations should be kept in mind: vehicle owners could only provide one Vehicle-to-Grid service at a time. Additionally, values for direct compensation when providing imbalance services should be considered carefully.

Future work could aim at addressing the limitations described above but also broaden the scope of the total cost of ownership calculation to better understand the interaction between charging locations and electric vehicles. Thereby, the methodology could be extended to a more holistic approach by for example including the end-of-life treatment of the propulsion battery. This could help in establishing a circular economy. Additionally, 
future studies should also evaluate if the conventional total cost of ownership is still appropriate for assessing increasingly complex interdependencies as outlined in this study.

Author Contributions: Conceptualization, D.H. and C.D.C.; methodology, D.H. and Q.D.C.; validation, Q.D.C., C.D.C. and N.S.; writing-original draft preparation, D.H.; writing-review and editing, C.D.C. and N.S.; visualization, D.H. and N.S.; supervision, C.D.C., N.S. and M.M.; project administration, T.C. and M.M; funding acquisition, T.C. and M.M. All authors have read and agreed to the published version of the manuscript.

Funding: This research was funded by the Agency for Innovation and Entrepreneurship (VLAIO) under the grant number HBC.2018.0519.

Conflicts of Interest: The authors declare no conflict of interest.

\section{Abbreviations}

The following abbreviations are used in this manuscript:

\begin{tabular}{|c|c|}
\hline V2G & Vehicle-to-Grid \\
\hline TCO & Total Cost of Ownership \\
\hline EV & Electric vehicle \\
\hline GHG & Greenhouse gas \\
\hline LLB & Local load balance \\
\hline IS & Imbalance service \\
\hline PM & Profit margin \\
\hline $\mathrm{LH}$ & Location holder \\
\hline $\mathrm{CPO}$ & Charge point operator \\
\hline MSP & Mobility service provider \\
\hline C & Costs occurring during the ownership \\
\hline $\mathrm{t}$ & Time expressed as the number of years \\
\hline $\mathrm{m}$ & Driven mileage during the ownership time expressed in $\mathrm{km}$ \\
\hline CAPEX & Capital expenditures \\
\hline OPEX & Operating expenditures \\
\hline NPV & Net present value \\
\hline$A_{t}$ & One-time costs at time $t$ \\
\hline$A_{0}$ & Annual reoccurring costs \\
\hline $\mathrm{r}$ & Real discount rate \\
\hline$C M_{d}$ & Direct compensation when providing V2G services \\
\hline$C M_{i}$ & Indirect compensation when providing V2G services \\
\hline$C_{V 2 G e}$ & Consumption costs when providing certain type of V2G services \\
\hline$C_{S e}$ & $\begin{array}{l}\text { Consumption costs in a standard charging case } \\
\text { (without providing any } \mathrm{V} 2 \mathrm{G} \text { service) }\end{array}$ \\
\hline$r_{I S}$ & V2G revenues from imbalance service \\
\hline$C_{e m}$ & V2G costs of the energy manager \\
\hline$C_{m i}$ & V2G costs for additional infrastructure maintenance \\
\hline$C_{S I}$ & Purchase costs of a standard charger for EVs \\
\hline$C_{V 2 G I}$ & Additional maintenance costs for V2G chargers \\
\hline$S C$ & Self-consumption \\
\hline$S C_{V 2 G}$ & $\begin{array}{l}\text { Self-consumption of PV electricity at a charging location where V2G } \\
\text { services is used for LLB }\end{array}$ \\
\hline$S C_{\text {Standard }}$ & Self-consumption of PV electricity at a charging location with standard EV charging \\
\hline$e_{S P V}$ & Amount of electricity in $\mathrm{kWh}$ that is consumed directly by the charging location \\
\hline$e_{P V}$ & $\begin{array}{l}\text { Amount of electricity in } \mathrm{kWh} \text { that is generated by the PV installation } \\
\text { at the charging location }\end{array}$ \\
\hline$L_{C L}$ & Overall load demand of a charging location \\
\hline$e_{G S}$ & Amount of electricity that the charging location is requesting from the grid \\
\hline$e_{G I}$ & Excess electricity generated by the PV installation and is fed back into the grid \\
\hline$e_{P V}$ & Amount of electricity that is generated by the PV installations \\
\hline$C_{P V}$ & Total cost of PV installation \\
\hline$C A P E X_{P V}$ & Capital expenditures of the PV installation \\
\hline
\end{tabular}




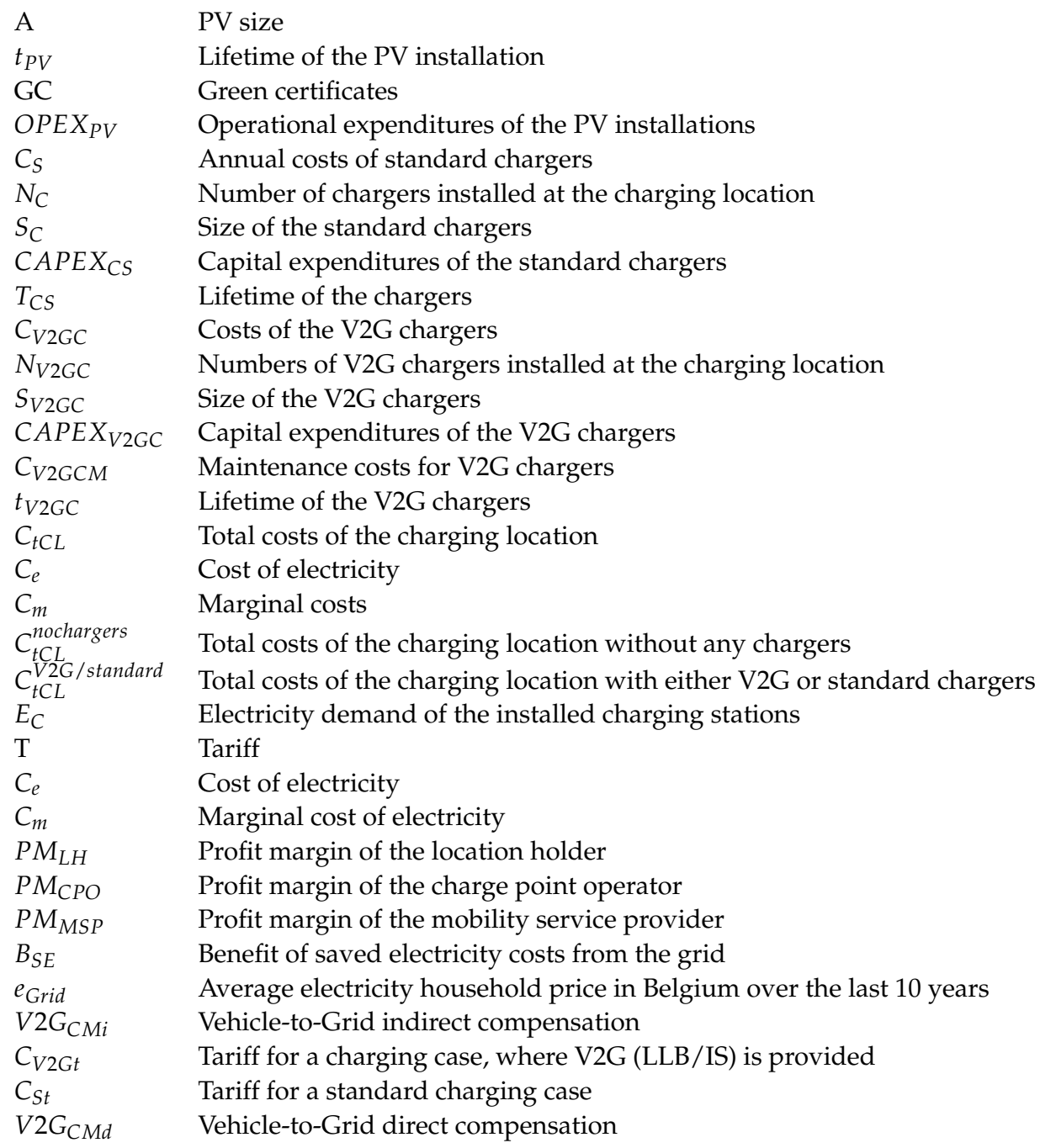

\section{Appendix A}

In the following, all standard TCO and V2G TCO for a Renault Zoe, a Hyundai Kona and a BMW i3 are presented.

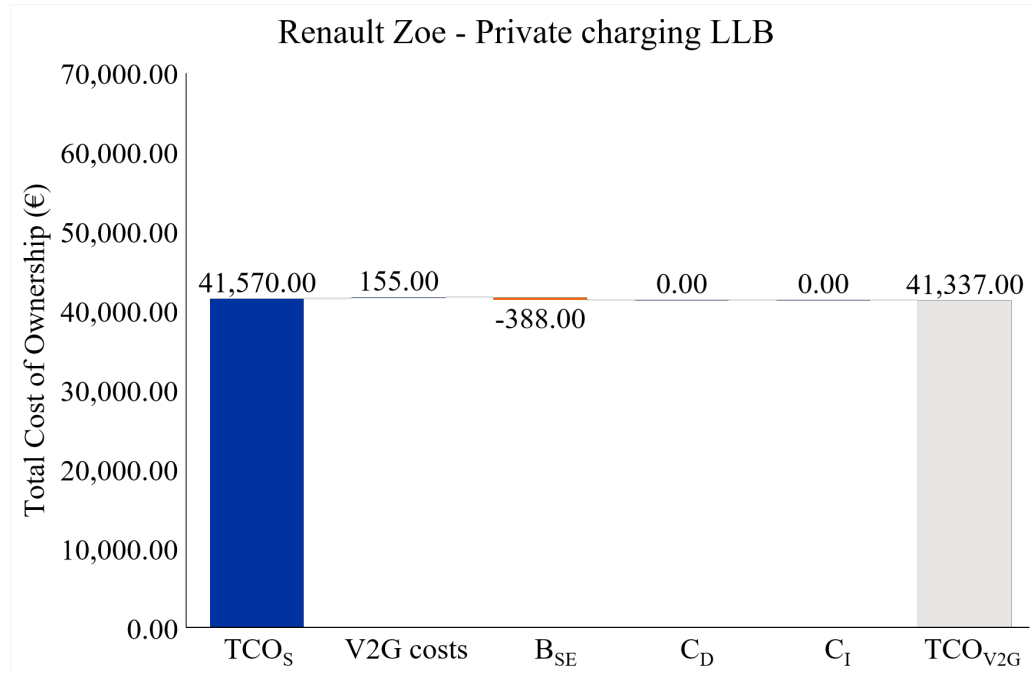

Figure A1. Standard and V2G TCO of a Renault Zoe in a private charging case providing LLB $\left(T C O_{S}=\right.$ Standard TCO, $B_{S E}=$ benefit of saved electricity costs from the grid, $C_{D}=$ direct compensation, $C_{I}=$ indirect compensation, $T C O_{V 2 G}=$ V2G TCO); source: own compilation). 


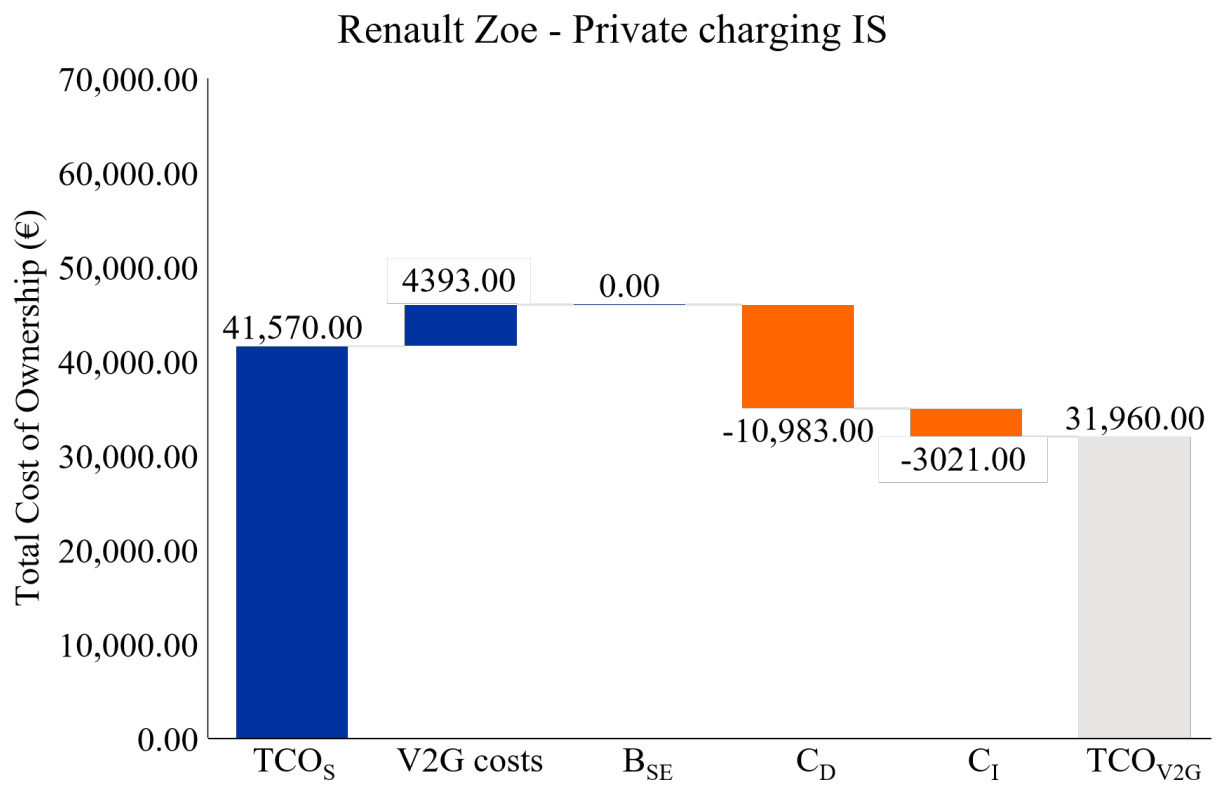

Figure A2. Standard and V2G TCO of a Renault Zoe in a private charging case providing IS $\left(\mathrm{TCO}_{S}=\right.$ Standard TCO, $B_{S E}=$ benefit of saved electricity costs from the grid, $C_{D}=$ direct compensation, $C_{I}=$ indirect compensation, $T C O_{V 2 G}=V 2 G$ TCO); source: own compilation).

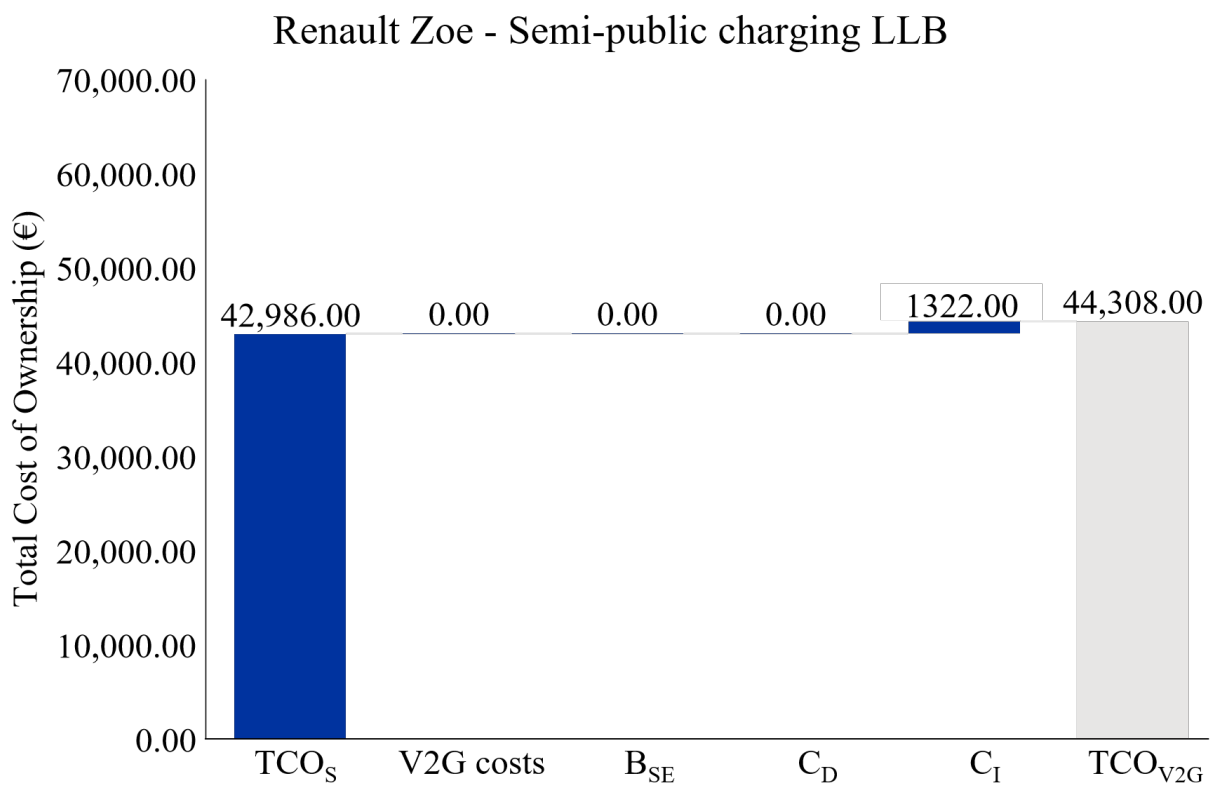

Figure A3. Standard and V2G TCO of a Renault Zoe in a semi-public charging case providing LLB $\left(T C O_{S}=\right.$ Standard TCO, $B_{S E}=$ benefit of saved electricity costs from the grid, $C_{D}=$ direct compensation, $C_{I}=$ indirect compensation, $T C O_{V 2 G}=$ V2G TCO); source: own compilation). 


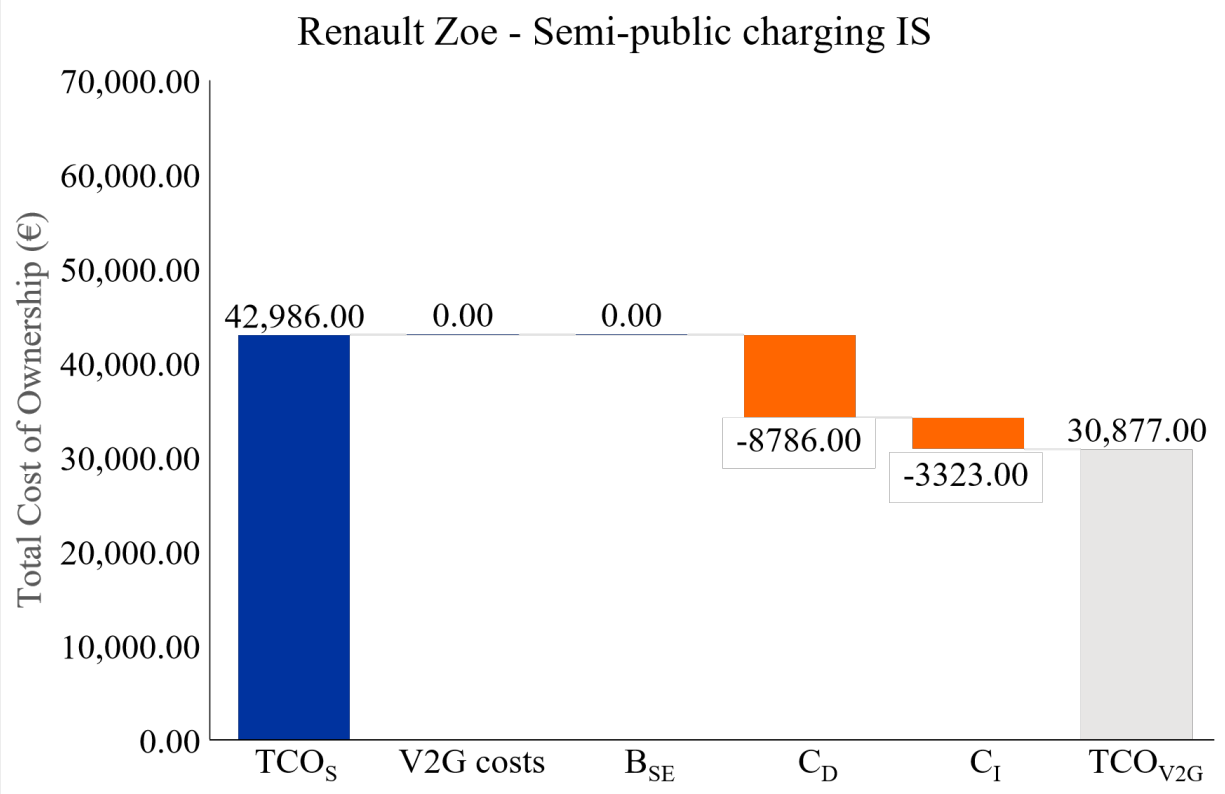

Figure A4. Standard and V2G TCO of a Renault Zoe in a semi-public charging case providing IS $\left(T C O_{S}=\right.$ Standard TCO, $B_{S E}=$ benefit of saved electricity costs from the grid, $C_{D}=$ direct compensation, $C_{I}=$ indirect compensation, $T C O_{V 2 G}=V 2 G$ TCO); source: own compilation).

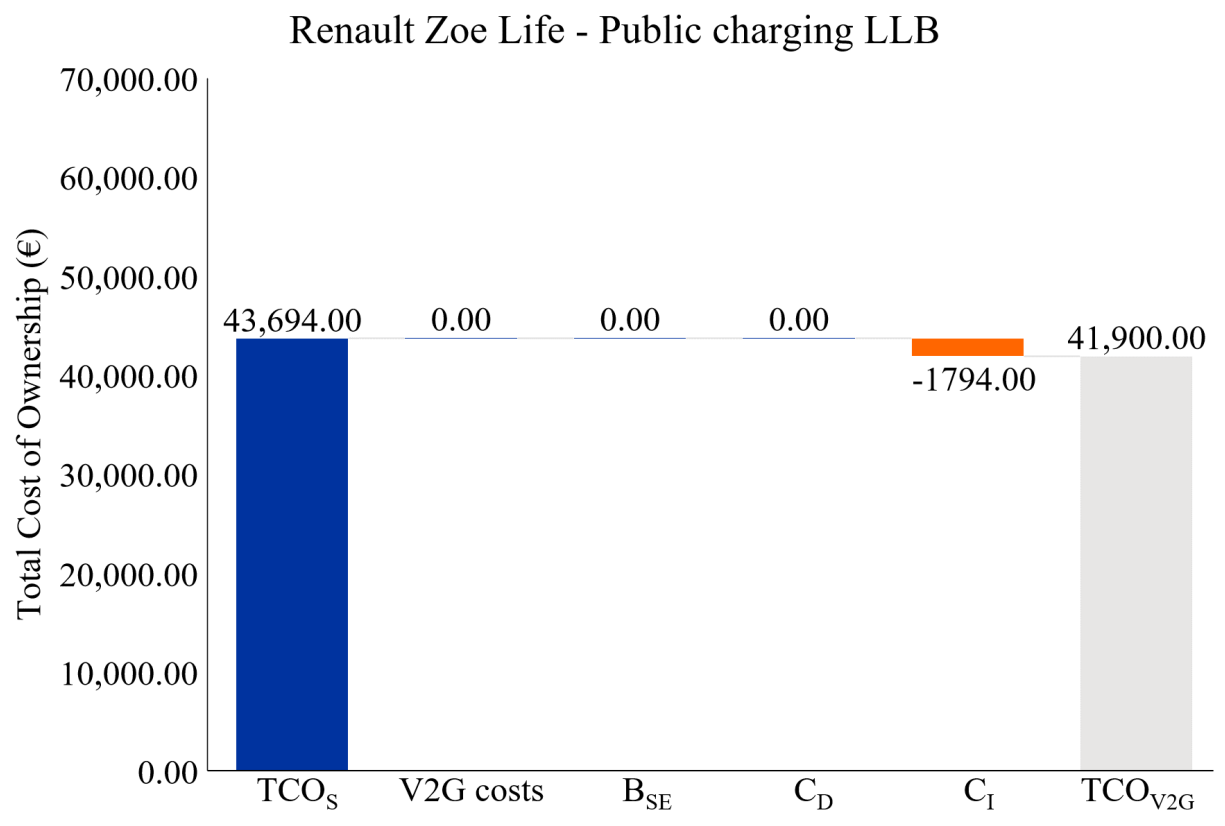

Figure A5. Standard and V2G TCO of a Renault Zoe in a public charging case providing LLB $\left(\mathrm{TCO}_{S}=\right.$ Standard TCO, $B_{S E}=$ benefit of saved electricity costs from the grid, $C_{D}=$ direct compensation, $C_{I}=$ indirect compensation, $T C O_{V 2 G}=V 2 G$ TCO); source: own compilation). 


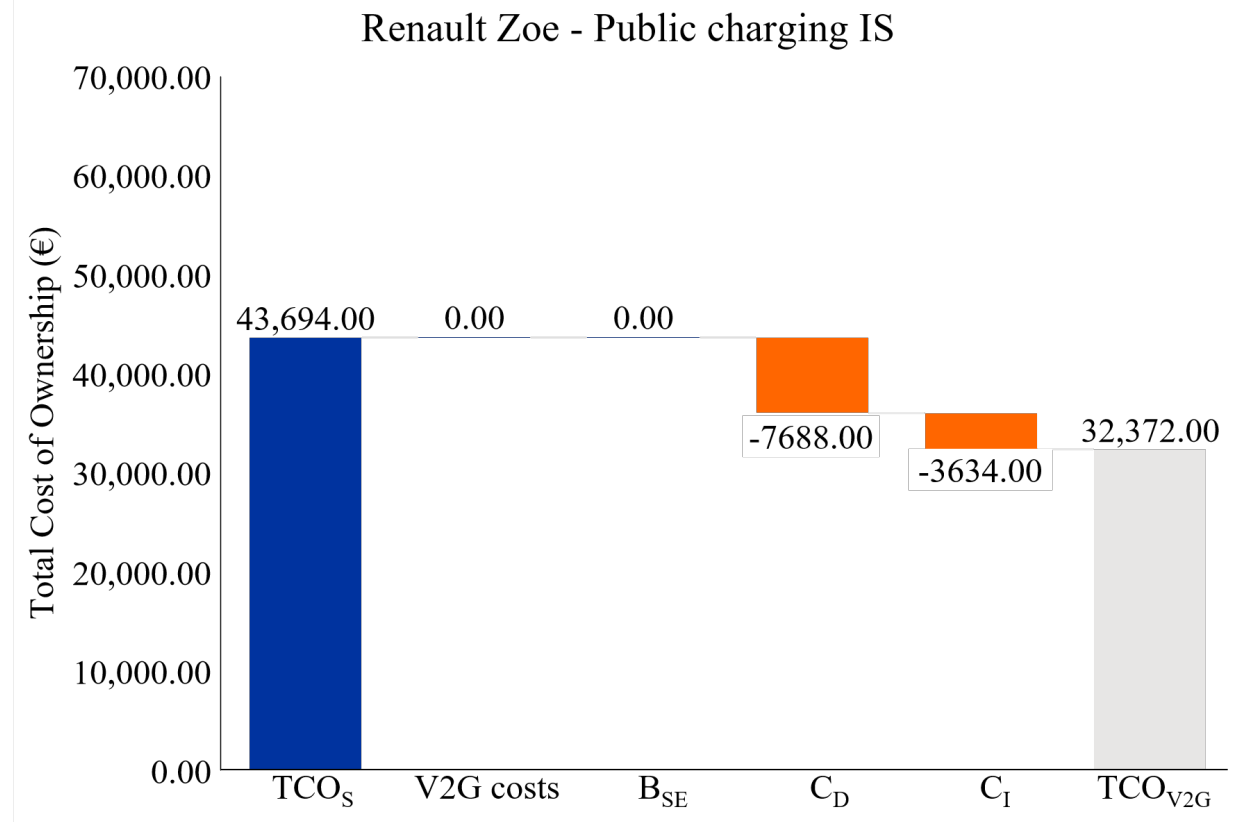

Figure A6. Standard and V2G TCO of a Renault Zoe in a public charging case providing IS $\left(\mathrm{TCO}_{S}=\right.$ Standard TCO, $B_{S E}=$ benefit of saved electricity costs from the grid, $C_{D}=$ direct compensation, $C_{I}=$ indirect compensation, $T C O_{V 2 G}=$ V2G TCO); source: own compilation).

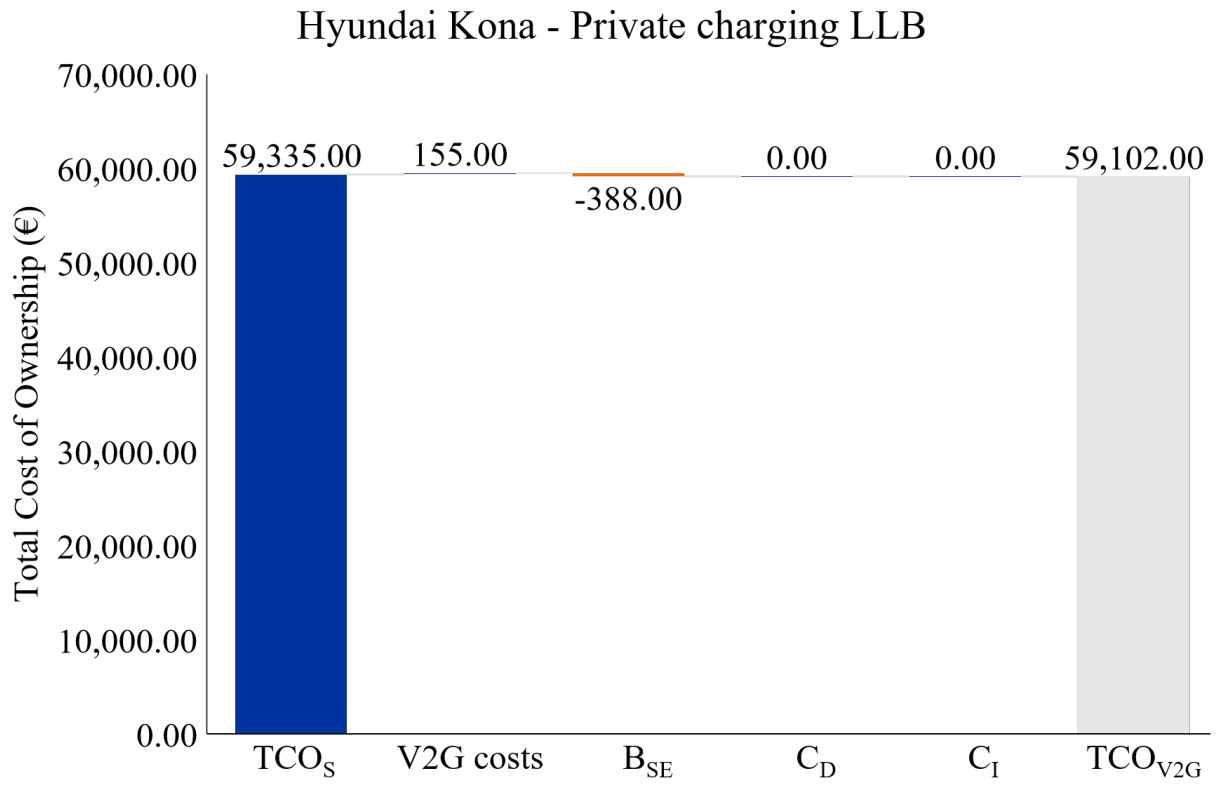

Figure A7. Standard and V2G TCO of a Hyundai Kona in a private charging case providing LLB $\left(\mathrm{TCO}_{S}=\right.$ Standard TCO, $B_{S E}=$ benefit of saved electricity costs from the grid, $C_{D}=$ direct compensation, $C_{I}=$ indirect compensation, $T C O_{V 2 G}=V 2 G$ TCO); source: own compilation). 


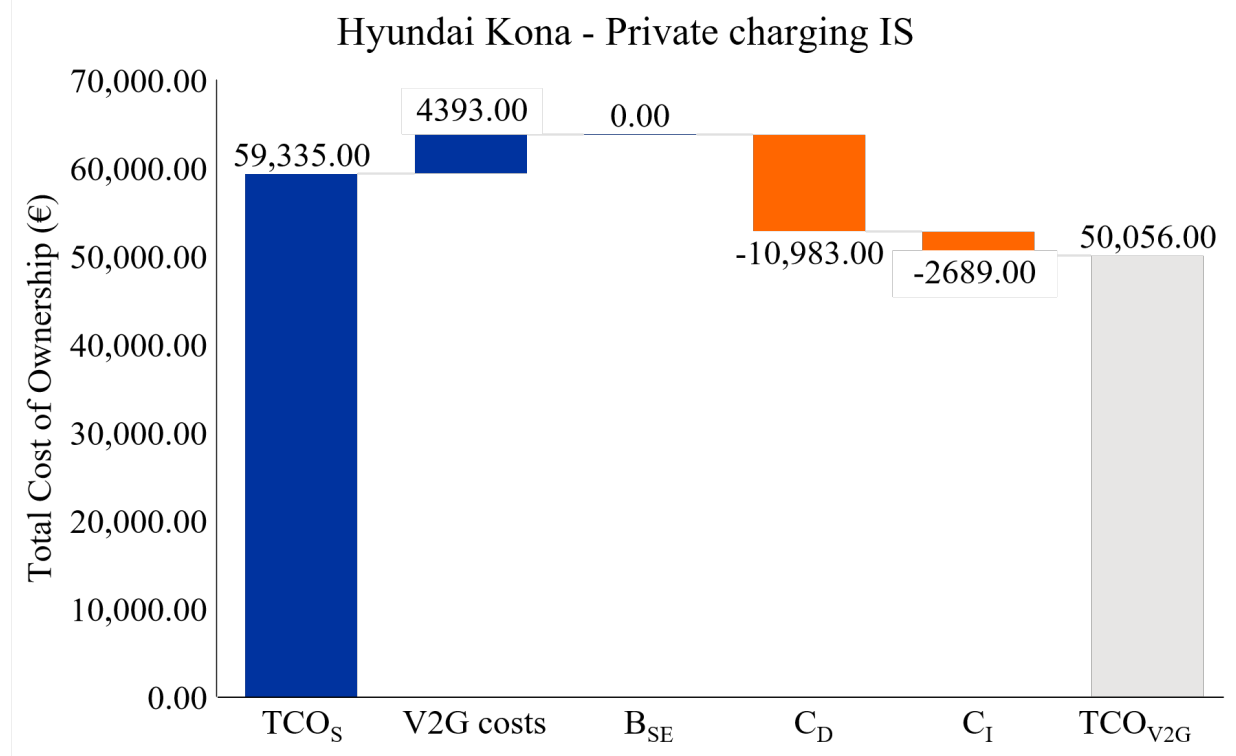

Figure A8. Standard and V2G TCO of a Hyundai Kona in a private charging case providing IS $\left(T C O_{S}=\right.$ Standard TCO, $B_{S E}=$ benefit of saved electricity costs from the grid, $C_{D}=$ direct compensation, $C_{I}=$ indirect compensation, $T C O_{V 2 G}=V 2 G$ TCO); source: own compilation).

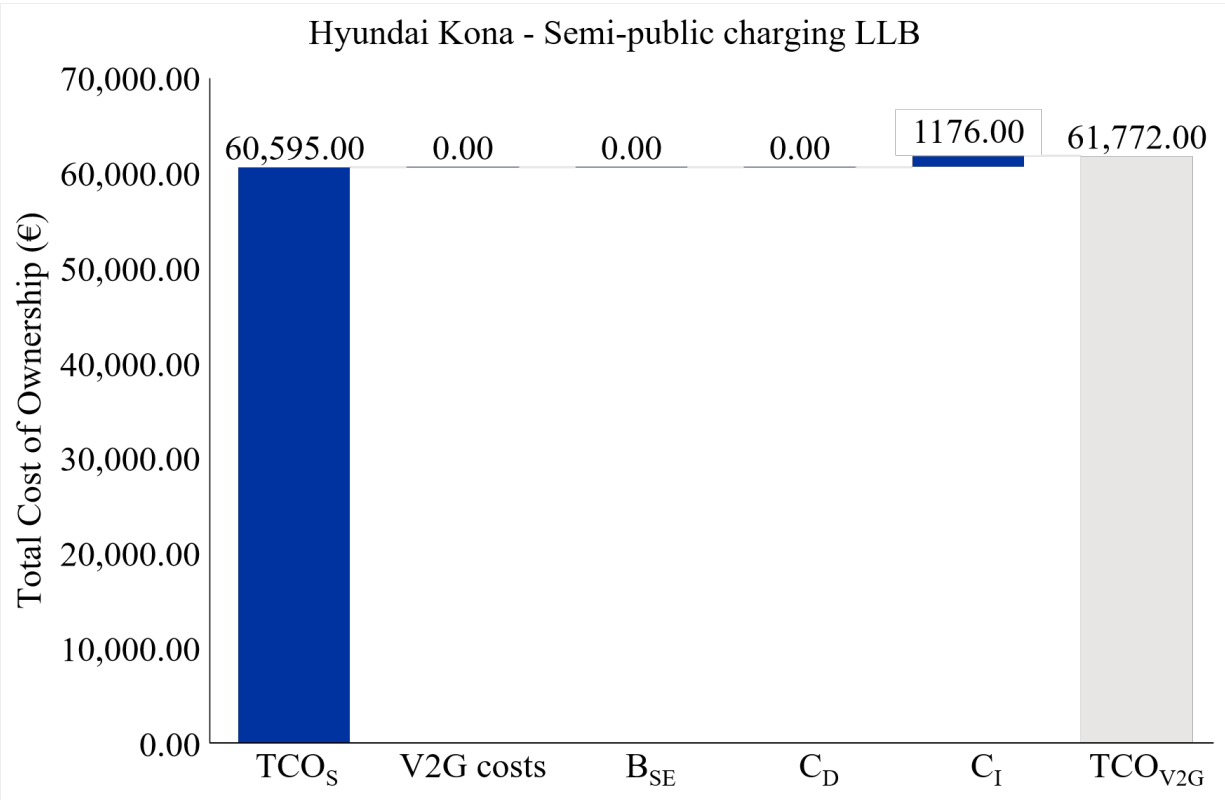

Figure A9. Standard and V2G TCO of a Hyundai Kona in a semi-public charging case providing LLB $\left(T C O_{S}=\right.$ Standard TCO, $B_{S E}=$ benefit of saved electricity costs from the grid, $C_{D}=$ direct compensation, $C_{I}=$ indirect compensation, $\left.\mathrm{TCO}_{V 2 G}=\mathrm{V} 2 \mathrm{G} \mathrm{TCO}\right)$; source: own compilation). 


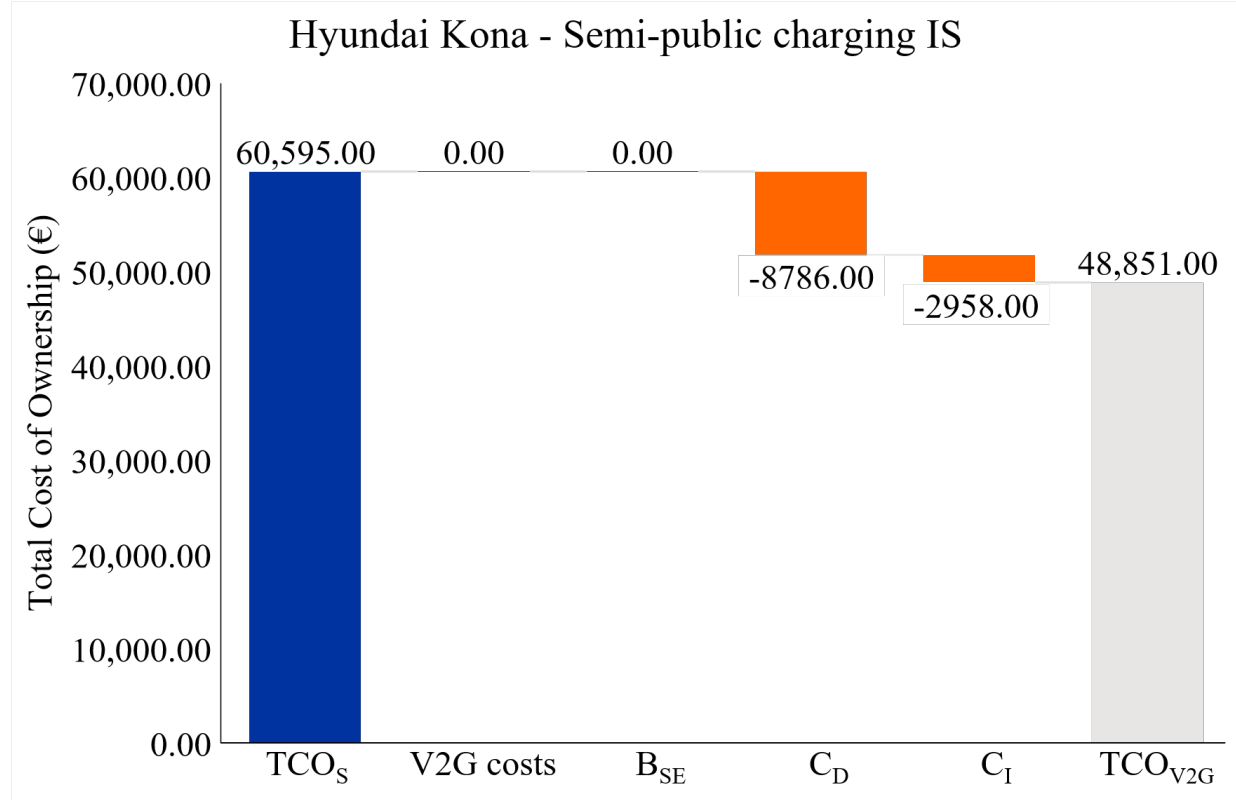

Figure A10. Standard and V2G TCO of a Hyundai Kona in a semi-public charging case providing IS $\left(\mathrm{TCO}_{S}=\right.$ Standard TCO, $B_{S E}=$ benefit of saved electricity costs from the grid, $C_{D}=$ direct compensation, $C_{I}=$ indirect compensation, $\left.\mathrm{TCO}_{V 2 \mathrm{G}}=\mathrm{V} 2 \mathrm{G} \mathrm{TCO}\right)$; source: own compilation).

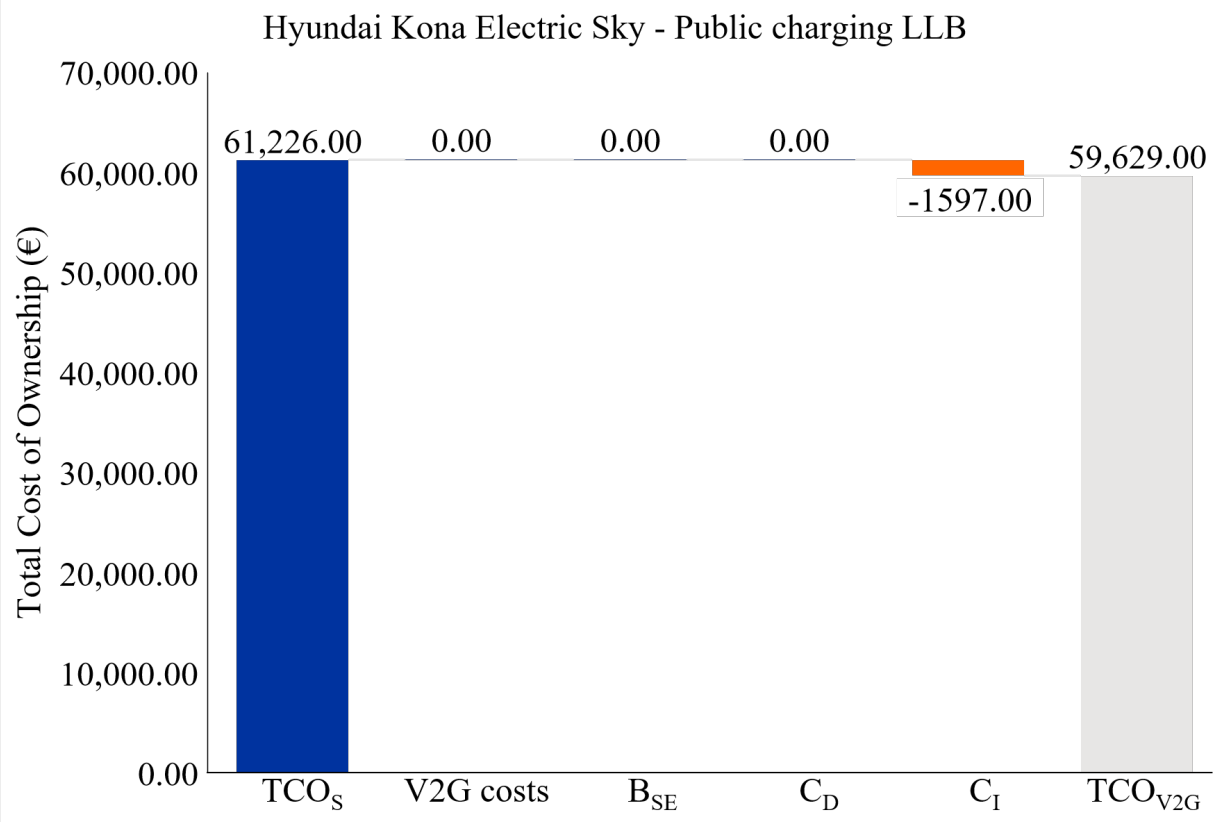

Figure A11. Standard and V2G TCO of a Hyundai Kona in a public charging case providing LLB $\left(T C O_{S}=\right.$ Standard TCO, $B_{S E}=$ benefit of saved electricity costs from the grid, $C_{D}=$ direct compensation, $C_{I}=$ indirect compensation, $\left.T_{C O} \mathrm{O}_{V 2}=\mathrm{V} 2 \mathrm{G} \mathrm{TCO}\right)$; source: own compilation). 


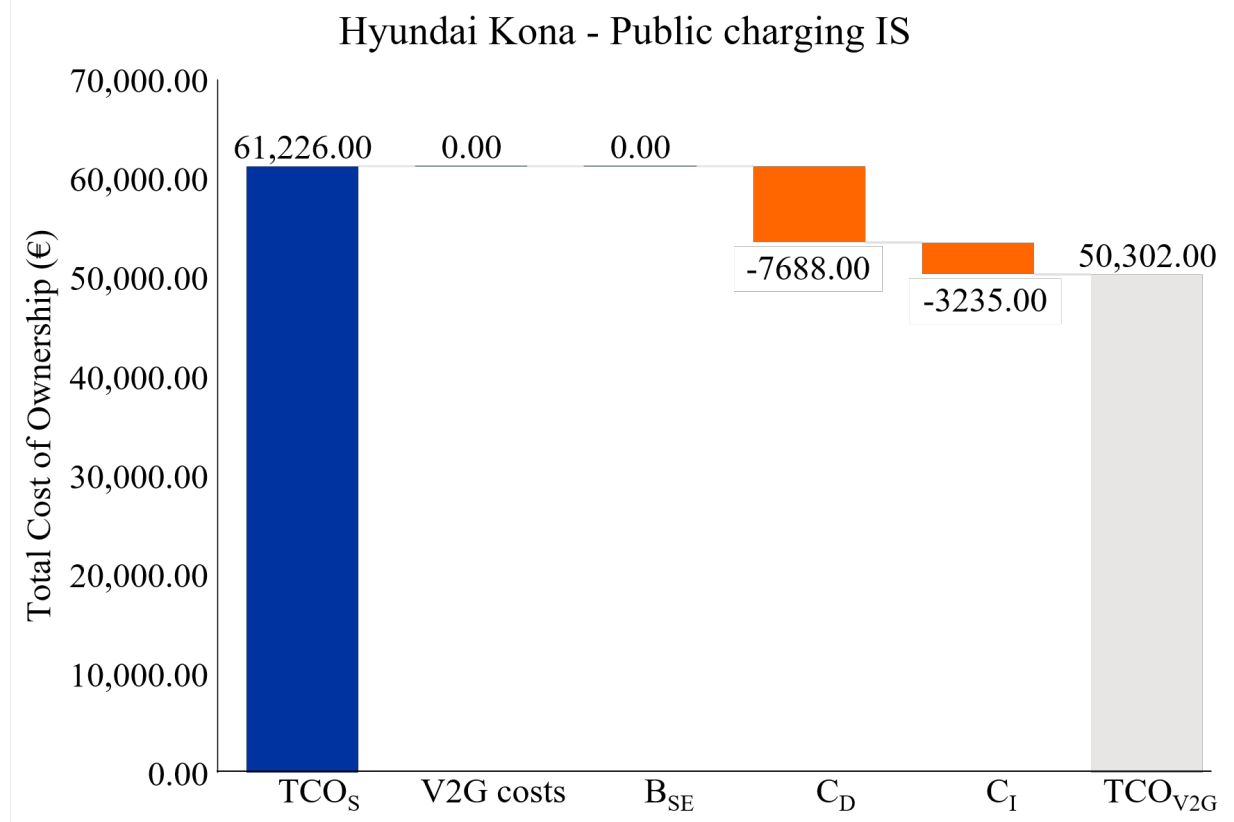

Figure A12. Standard and V2G TCO of a Hyundai Kona in a public charging case providing IS $\left(T C O_{S}=\right.$ Standard TCO, $B_{S E}=$ benefit of saved electricity costs from the grid, $C_{D}=$ direct compensation, $C_{I}=$ indirect compensation, $T_{C O} \mathrm{~V}_{V 2}=\mathrm{V} 2 \mathrm{G}$ TCO); source: own compilation).

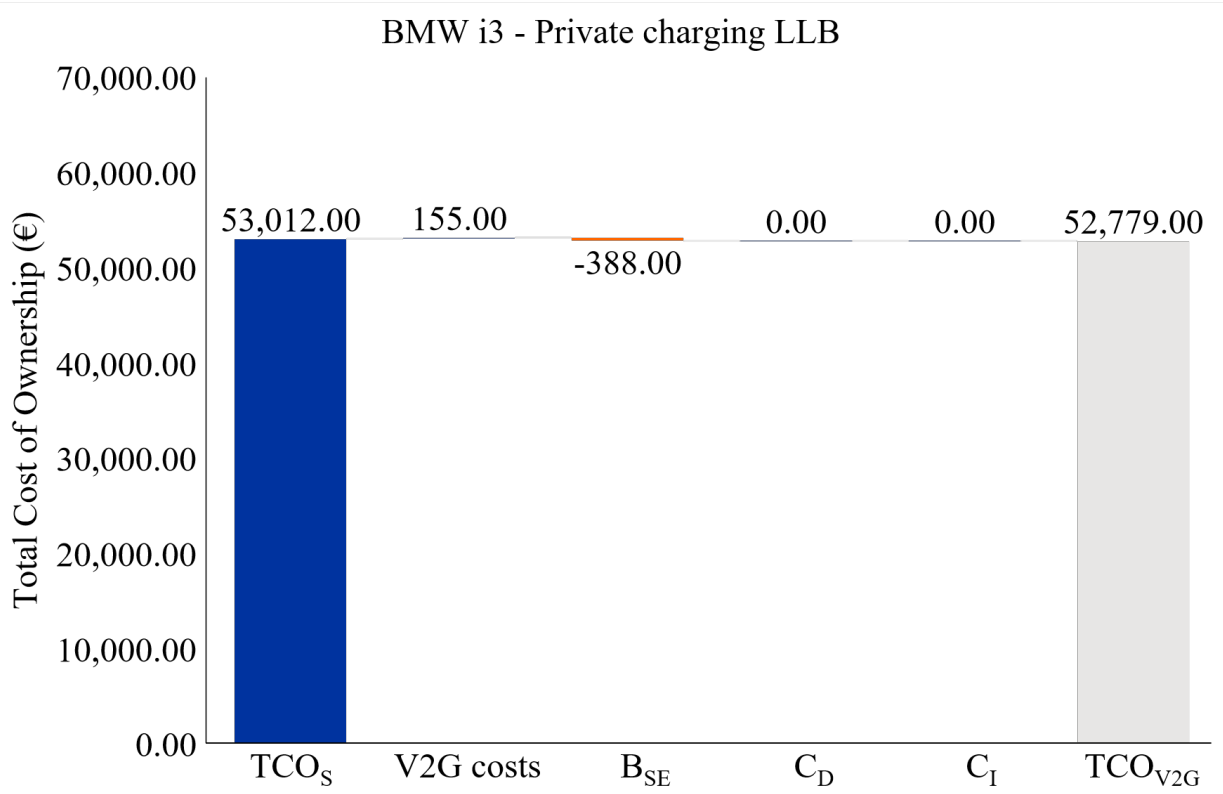

Figure A13. Standard and V2G TCO of a BMW i3 in a private charging case providing LLB $\left(\mathrm{TCO}_{S}=\right.$ Standard TCO, $B_{S E}=$ benefit of saved electricity costs from the grid, $C_{D}=$ direct compensation, $C_{I}=$ indirect compensation, $T_{C O} O_{V 2 G}=V 2 G$ TCO); source: own compilation). 
BMW i3 - Private charging IS

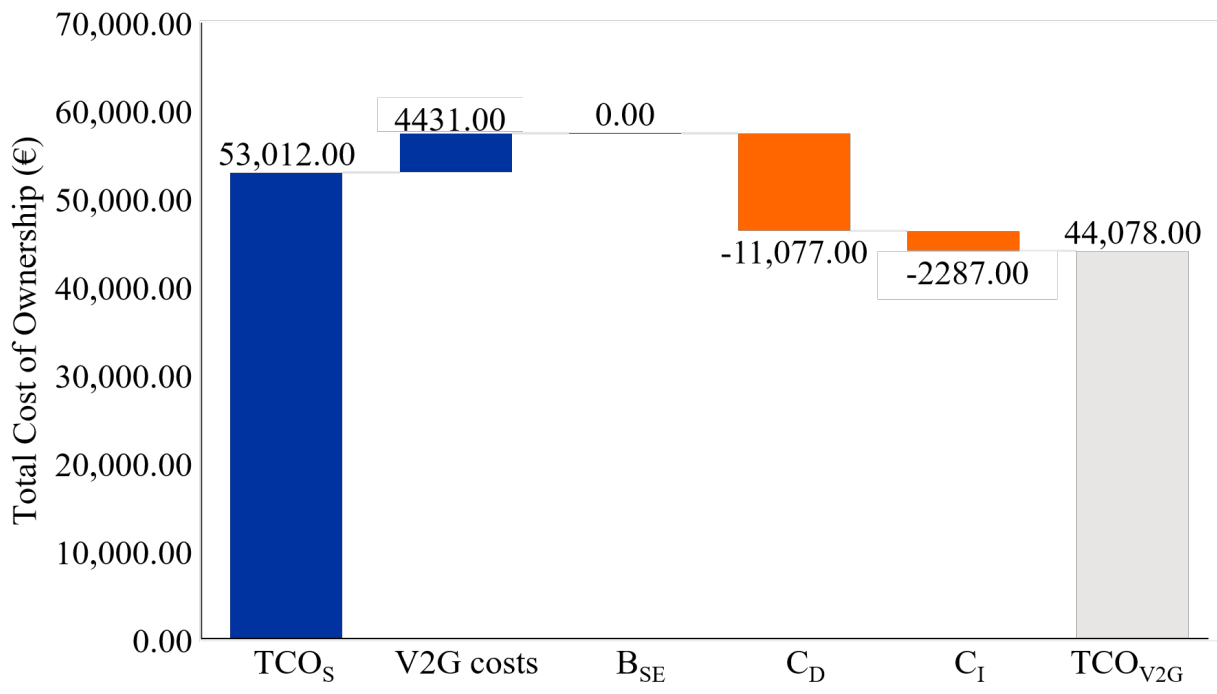

Figure A14. Standard and V2G TCO of a BMW i3 in a private charging case providing IS $\left(T C O_{S}=\right.$ Standard TCO, $B_{S E}=$ benefit of saved electricity costs from the grid, $C_{D}=$ direct compensation, $C_{I}=$ indirect compensation, $\mathrm{TCO}_{V 2 \mathrm{G}}=\mathrm{V} 2 \mathrm{G} \mathrm{TCO}$ ); source: own compilation).

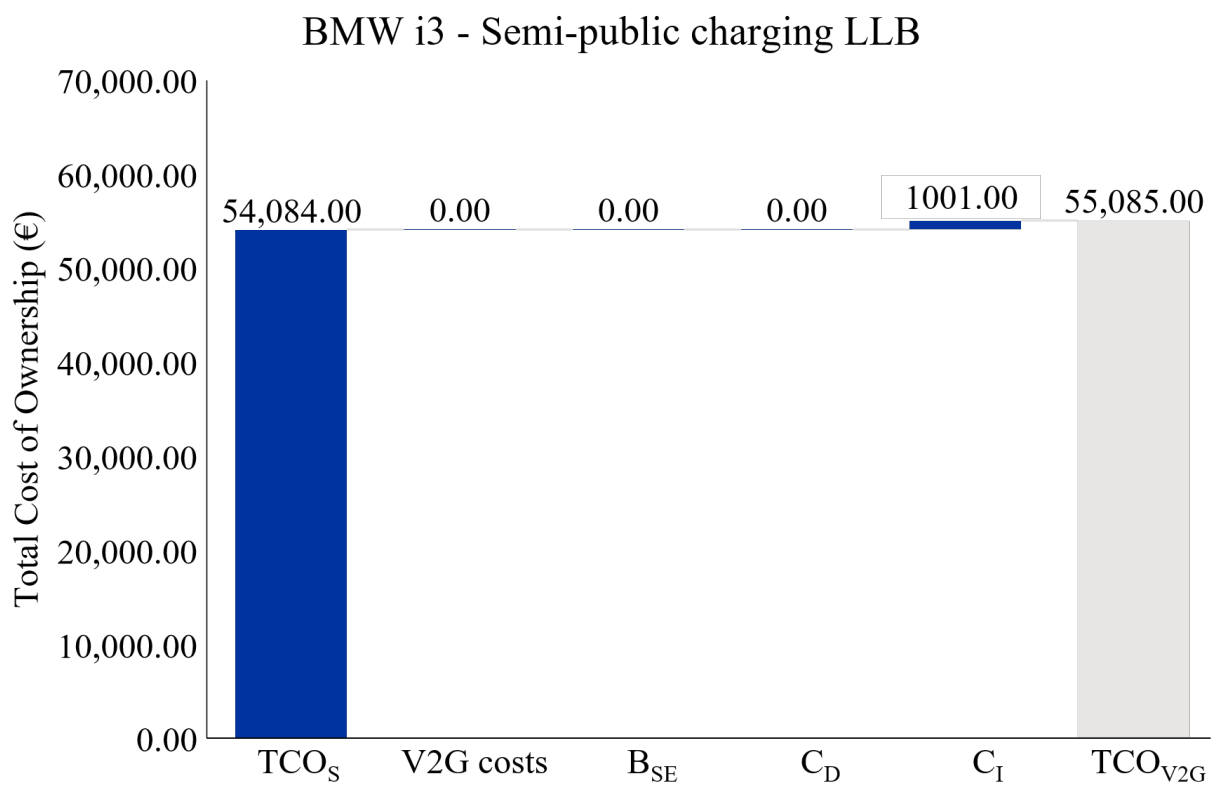

Figure A15. Standard and V2G TCO of a BMW i3 in a semi-public charging case providing LLB $\left(T C O_{S}=\right.$ Standard TCO, $B_{S E}=$ benefit of saved electricity costs from the grid, $C_{D}=$ direct compensation, $C_{I}=$ indirect compensation, $T C O_{V 2 G}=V 2 G$ TCO); source: own compilation). 


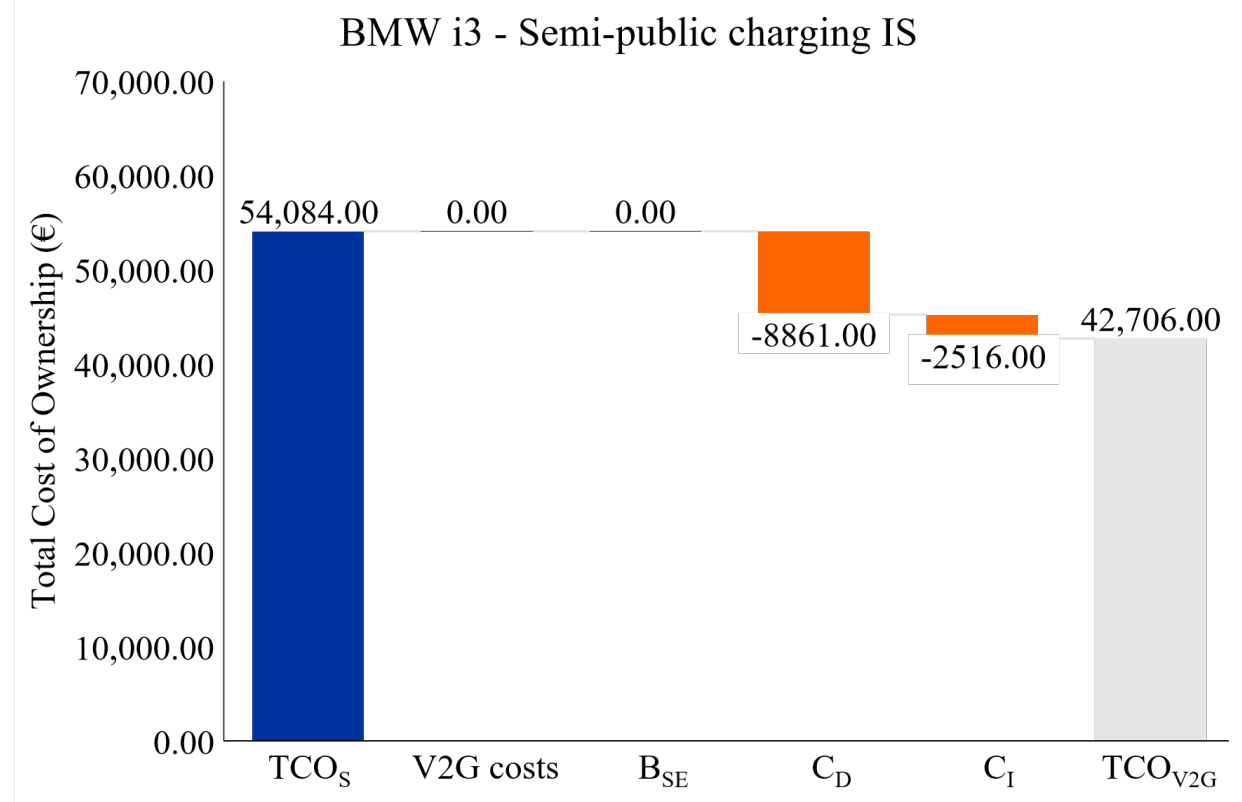

Figure A16. Standard and V2G TCO of a BMW i3 in a semi-public charging case providing IS $\left(\mathrm{TCO}_{S}=\right.$ Standard TCO, $B_{S E}=$ benefit of saved electricity costs from the grid, $C_{D}=$ direct compensation, $C_{I}=$ indirect compensation, $T C O_{V 2 G}=V 2 G$ TCO); source: own compilation).

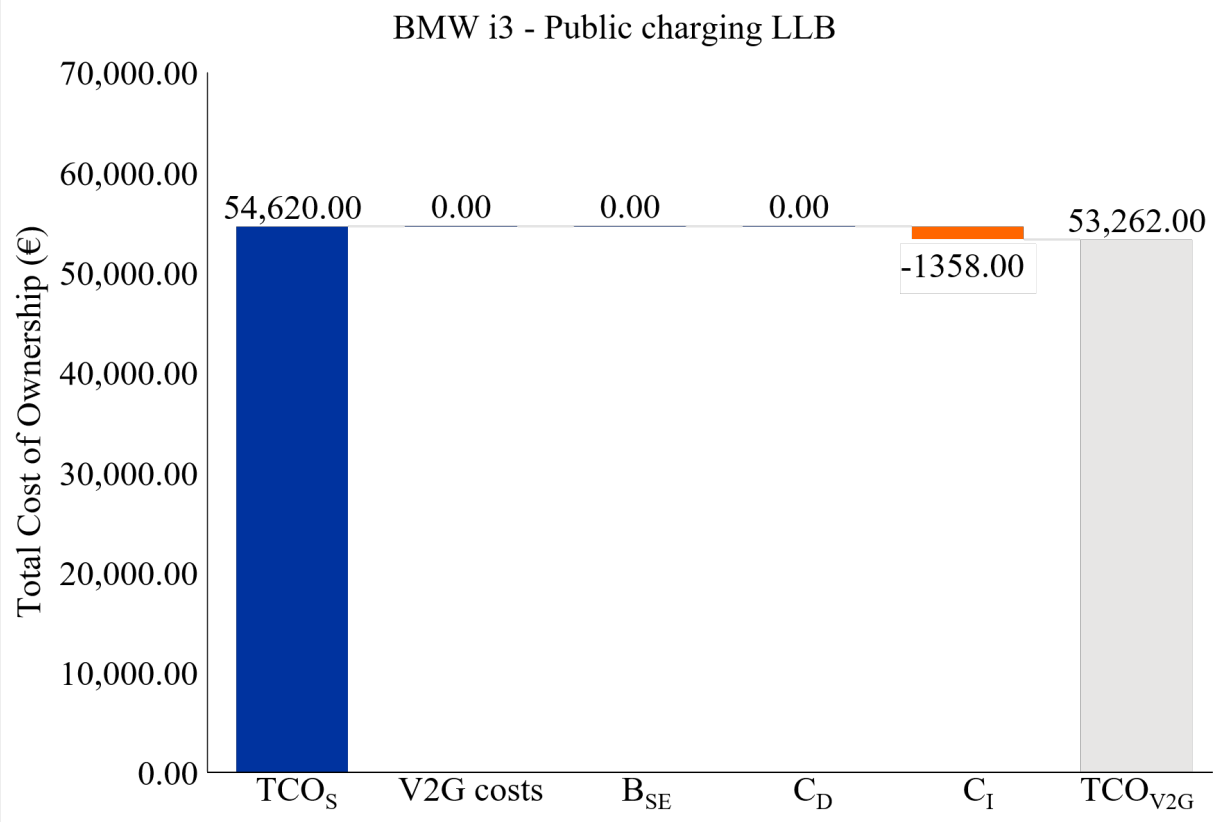

Figure A17. Standard and V2G TCO of a BMW i3 in a public charging case providing LLB $\left(T_{C O}=\right.$ Standard TCO, $B_{S E}=$ benefit of saved electricity costs from the grid, $C_{D}=$ direct compensation, $C_{I}=$ indirect compensation, $T_{C O} O_{V 2 G}=V 2 G$ TCO); source: own compilation). 


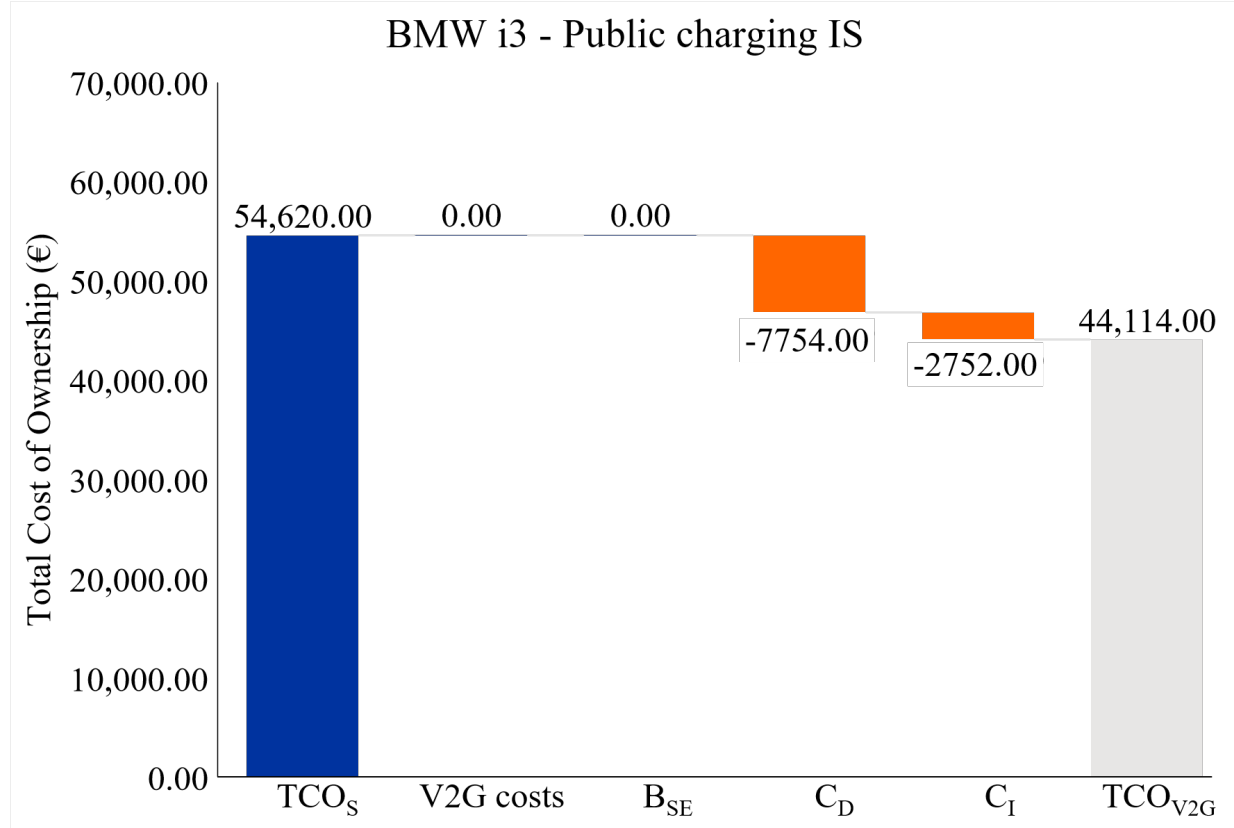

Figure A18. Standard and V2G TCO of a BMW i3 in a public charging case providing IS $\left(\mathrm{TCO}_{S}=\right.$ Standard TCO, $B_{S E}=$ benefit of saved electricity costs from the grid, $C_{D}=$ direct compensation, $C_{I}=$ indirect compensation, $\left.T C \mathrm{O}_{V 2 G}=\mathrm{V} 2 \mathrm{G} \mathrm{TCO}\right)$; source: own compilation).

\section{References}

1. The European Environment Agency. EEA Greenhouse Gases-Data Viewer. Available online: https://www.eea.europa.eu/dataand-maps/data/data-viewers / greenhouse-gases-viewer (accessed on 1 October 2021).

2. Saldaña, G.; Martin, J.I.S.; Zamora, I.; Asensio, F.J.; Oñederra, O. Electric vehicle into the grid: Charging methodologies aimed at providing ancillary services considering battery degradation. Energies 2019, 12, 2443. [CrossRef]

3. Pearre, N.S.; Ribberink, H. Review of research on V2X technologies, strategies, and operations. Renew. Sustain. Energy Rev. 2019, 105, 61-70. [CrossRef]

4. Amamra, S.A.; Marco, J. Vehicle-to-Grid Aggregator to Support Power Grid and Reduce Electric Vehicle Charging Cost. IEEE Access 2019, 7, 178528-178538. [CrossRef]

5. Kiaee, M.; Cruden, A.; Sharkh, S. Estimation of cost savings from participation of electric vehicles in vehicle to grid (V2G) schemes. J. Mod. Power Syst. Clean Energy 2015, 3, 249-258. [CrossRef]

6. Falkoni, A.; Pfeifer, A.; Krajačić, G. Vehicle-to-Grid in Standard and Fast Electric Vehicle Charging: Comparison of Renewable Energy Source Utilization and Charging Costs. Energies 2020, 13, 1510. [CrossRef]

7. Bishop, J.D.; Axon, C.J.; Bonilla, D.; Banister, D. Estimating the grid payments necessary to compensate additional costs to prospective electric vehicle owners who provide vehicle-to-grid ancillary services. Energy 2016, 94, 715-727. [CrossRef]

8. Su, X.; Yue, H.; Chen, X. Cost minimization control for electric vehicle car parks with vehicle to grid technology. Syst. Sci. Control Eng. 2020, 8, 422-433. [CrossRef]

9. Heilmann, C.; Friedl, G. Factors influencing the economic success of grid-to-vehicle and vehicle-to-grid applications-A review and meta-analysis. Renew. Sustain. Energy Rev. 2021, 145, 111115. [CrossRef]

10. Li, X.; Tan, Y.; Liu, X.; Liao, Q.; Sun, B.; Cao, G.; Li, C.; Yang, X.; Wang, Z. A cost-benefit analysis of V2G electric vehicles supporting peak shaving in Shanghai. Electr. Power Syst. Res. 2020, 179, 106058. [CrossRef]

11. Brown, R.J. A new marketing tool: Life-cycle costing. Ind. Mark. Manag. 1979, 8, 109-113. [CrossRef]

12. Lebeau, K.; Lebeau, P.; Macharis, C.; Van Mierlo, J. How expensive are electric vehicles? A total cost of ownership analysis. World Electr. Veh. J. 2013, 6, 996-1007. [CrossRef]

13. Vanhaverbeke, L.; Schreurs, D.; De Clerck, Q.; Messagie, M.; Van Mierlo, J. Total cost of ownership of electric vehicles incorporating Vehicle to Grid technology. In Proceedings of the 2017 Twelfth International Conference on Ecological Vehicles and Renewable Energies (EVER), Monte Carlo, Monaco, 11-13 April 2017; pp. 1-6. [CrossRef]

14. De Clerck, Q.; van Lier, T.; Messagie, M.; Macharis, C.; Van Mierlo, J.; Vanhaverbeke, L. Total Cost for Society: A persona-based analysis of electric and conventional vehicles. Transp. Res. Part D Transp. Environ. 2018, 64, 90-110. [CrossRef]

15. Letmathe, P.; Suares, M. A consumer-oriented total cost of ownership model for different vehicle types in Germany. Transp. Res. Part D Transp. Environ. 2017, 57, 314-335. [CrossRef]

16. Van Velzen, A.; Annema, J.A.; van de Kaa, G.; van Wee, B. Proposing a more comprehensive future total cost of ownership estimation framework for electric vehicles. Energy Policy 2019, 129, 1034-1046. [CrossRef] 
17. Ellram, L.M. Total cost of ownership. Int. J. Phys. Distrib. Logist. Manag. 1995, 25, 4-23. [CrossRef]

18. Ferrin, B.G.; Plank, R.E. Total Cost of Ownership Models: An Exploratory Study. J. Supply Chain Manag. 2002, 38, 18-29. [CrossRef]

19. Hagman, J.; Ritzén, S.; Stier, J.J.; Susilo, Y. Total cost of ownership and its potential implications for battery electric vehicle diffusion. Res. Transp. Bus. Manag. 2016, 18, 11-17. [CrossRef]

20. Department of Education and Early Development, State of Alaska. Life Cycle Cost Analysis Handbook; With Contributions by Tim Mearig, Nathan Coffee, and Michael Morgan; Department of Education and Early Development, State of Alaska: Juneau, AK, USA, 1999; 31p.

21. Erdogan, N.; Erden, F.; Kisacikoglu, M. A fast and efficient coordinated vehicle-to-grid discharging control scheme for peak shaving in power distribution system. J. Mod. Power Syst. Clean Energy 2018, 6, 555-566. [CrossRef]

22. Luthander, R.; Widén, J.; Nilsson, D.; Palm, J. Photovoltaic self-consumption in buildings: A review. Appl. Energy 2015, 142, 80-94. [CrossRef]

23. Elia. Keeping the Balance. Available online: https://www.elia.be/en/electricity-market-and-system/system-services/keepingthe-balance (accessed on 21 October 2021).

24. Steward, D. Critical Elements of Vehicle-to-Grid (V2G) Economics; National Renewable Energy Laboratory: Golden, CO, USA, 2017.

25. De Cauwer, C.; Guillemot, A.; Cragues, G.; Van Mierlo, J.; Coosemans, T.; Messagie, M. Towards EU-wide Interoperability of charging infrastructure for electric vehicles. In Proceedings of the 31st International Electric Vehicle Symposium \& Exhibition (EVS31), Kobe, Japan, 30 September-4 October 2018; pp. 1-7.

26. Statistic Research Department. Electricity Prices for Households in Belgium from 2010 to 2020, Semi-Annually (in Euro Cents per Kilowatt-Hour). Available online: https://www.statista.com/statistics/418067/electricity-prices-for-households-in-belgium/ (accessed on 15 October 2021).

27. Syed, A.; Crispeels, T.; Marin, J.J.R.; Cardellini, G.; De Cauwer, C.; Coosemans, T.; Van Mierlo, J.; Messagie, M. A Novel Method to Value the EV-fleet's Grid Balancing Capacity. In Proceedings of the 33rd Electric Vehicle Symposium (EVS33), Portland, OR, USA, 14-17 June 2020.

28. Baure, G.; Dubarry, M. Durability and Reliability of EV Batteries under Electric Utility Grid Operations: Impact of Frequency Regulation Usage on Cell Degradation. Energies 2020, 13, 2494. [CrossRef]

29. Li, Y.; Messagie, M.; Berecibar, M.; Hegazy, O.; Abdel-Monem, M.; Omar, N.; Devroey, L.; Van Mierlo, J. The impact of the vehicle-to-grid strategy on lithium-ion battery ageing process. In Proceedings of the 31st International Electric Vehicle Symposium \& Exhibition and International Electric Vehicle Technology Conference (EVS 31 \& EVTeC 2018), Kobe, Japan, 30 September-3 October 2018.

30. Thingvad, A.; Marinelli, M. Influence of V2G Frequency Services and Driving on Electric Vehicles Battery Degradation in the Nordic Countries. In Proceedings of the 31st International Electric Vehicle Symposium \& Exhibition and International Electric Vehicle Technology Conference (EVS 31 \& EVTeC 2018), Kobe, Japan, 30 September-3 October 2018.

31. Thingvad, A.; Calearo, L.; Andersen, P.; Marinelli, M. Empirical Capacity Measurements of Electric Vehicles Subject to Battery Degradation from V2G Service. IEEE Trans. Veh. Technol. 2021, 70, 7547-7557. [CrossRef]

32. Uddin, K.; Dubarry, M.; Glick, M.B. The viability of vehicle-to-grid operations from a battery technology and policy perspective. Energy Policy 2018, 113, 342-347. [CrossRef]

33. Wang, D.; Coignard, J.; Zeng, T.; Zhang, C.; Saxena, S. Quantifying electric vehicle battery degradation from driving vs. vehicle-to-grid services. J. Power Sources 2016, 332, 193-203. [CrossRef]

34. Bishop, J.D.; Axon, C.J.; Bonilla, D.; Tran, M.; Banister, D.; McCulloch, M.D. Evaluating the impact of V2G services on the degradation of batteries in PHEV and EV. Appl. Energy 2013, 111, 206-218. [CrossRef]

35. Elia. Auctions and Sale of Flemish Certificates. Available online: https://www.elia.be/en/customers/green-certificates-andlevies-tariffs / flanders-auctions-for-gc (accessed on 27 October 2021).

36. Wallbox. Copper S. Available online: https://wallbox.com/nl_be/opladers/copper-s (accessed on 30 September 2021).

37. Fédération Belge et Luxembourgeoise de l'Automobile et du Cycle. Evolution de l'âge Moyen du Parc des Voitures. Available online: http:/ / www.febiac.be/public/statistics.aspx?FID=23\%0B\&\%0Blang=NL (accessed on 24 April 2021).

38. Kwanten, M. Kilometers Afgelegd Door Belgische Voertuigen. Available online: https://mobilit.belgium.be/sites/default/files/ rapport_kilometers_2017_nl.pdf (accessed on 24 April 2021).

39. European Central Bank. Yield Curve Spot Rate, 8-Year Maturity—Government Bond, Nominal, All Issuers Whose Rating Is Triple A-Euro Area (Changing Composition). Available online: https://sdw.ecb.europa.eu/quickview.do;jsessionid=05CF72C1 ACE4E251519A89EE4FCF2155?SERIES_KEY=165.YC.B.U2.EUR.4F.G_N_A.SV_C_YM.SR_8Y\&start=15-06-2012\&end=15-06-20 20\&submitOptions. $x=0 \&$ submitOptions. $y=0 \&$ trans=N (accessed on 24 April 2021).

40. European Central Bank. Euro Foreign Exchange Reference Rates: US Dollar (USD). Available online: https://www.ecb. europa.eu/stats/policy_and_exchange_rates/euro_reference_exchange_rates/html/eurofxref-graph-usd.en.html (accessed on 24 April 2021).

41. Nissan. Liste de Prix Juin 2020. Available online: https://www.nissan.lu/vehicules/neufs/leaf/configurateur.html\#configure/ BALw / A/version (accessed on 24 April 2021). 
42. Renault. Renault Nieuwe ZOE LIFE R110. Available online: https://nl.renault.be/elektrische-wagens/ontdek-nieuwezoe/configurator.html?conf=https $\% 3 \mathrm{~A} \% 2 \mathrm{~F} \% 2 \mathrm{Fbe}$. co.rplug.renault.com\%2Fc\%2FBACbi0AhhAjEzE2E1\%2FAzpbw (accessed on 24 April 2021).

43. Hyundai. KONA Electric. Available online: https://www.hyundai.no/modeller/kona-electric/ (accessed on 24 April 2021).

44. BMW. The i3-Prijslijst 03/2020. Available online: https://www.bmw.de/de/neufahrzeuge/bmw-i/i3/2020/bmw-i3 -ueberblick.html (accessed on 24 April 2021).

45. Overheid, V. Vehicle Registration Tax. Available online: https:/ / www.vlaanderen.be/en/vehicle-registration-tax (accessed on 21 June 2021).

46. AXA. Assurance Auto. Available online: https://eauto.axa.be/eauto/default.aspx?ID=mIEzLWOSEMMsU4ZeWfo5 uMpKZKVNfnhhiOBA\%2BVLS_vgdLv7XtqmjGU\%2Baa2VYBI93GsO6MwRIjQWcJP9_prfS9\%2BEmmg\&U=1A644987EDC1 F62DAAF96536F7EB74F6\&intid=car_mainpage_banner-cta-right (accessed on 25 June 2021).

47. Michelin. Nieuwe Michelin E-Primacy Banden. Available online: https://www.michelin.be/nl/auto/home-auto (accessed on 22 June 2021).

48. QTeam. 205/55 R 16 91H CROSSCLIMATE+ TL. Available online: https://www.qteam.be/nl/shop/detail/michelincrossclimate $/ 3528704554355 /$ ?utm_source=click2buy\&utm_campaign=manufacturer\&utm_medium=referral\&utm_term $=$ michelin (accessed on 22 June 2021).

49. Overheid, V. Vrijstelling Voor Pure Elektrische en Pure Waterstofvoertuigen. Available online: https://www.vlaanderen.be/ vrijstelling-voor-pure-elektrische-en-pure-waterstofvoertuigen (accessed on 6 June 2021).

50. Overheid, V. Tarieven Technische Keuring. Available online: https:/ /www.vlaanderen.be/tarieven-technische-keuring (accessed on 6 June 2021).

51. Berckmans, G.; Messagie, M.; Smekens, J.; Omar, N.; Vanhaverbeke, L.; Van Mierlo, J. Cost Projection of State of the Art Lithium-Ion Batteries for Electric Vehicles Up to 2030. Energies 2017, 10, 1314. [CrossRef]

52. Van Heuveln, K.; Ghotge, R.; Annema, J.A.; van Bergen, E.; van Wee, B.; Pesch, U. Factors influencing consumer acceptance of vehicle-to-grid by electric vehicle drivers in the Netherlands. Travel Behav. Soc. 2021, 24, 34-45. [CrossRef]

53. Kyriakopoulos, G.L. Environmental Legislation in European and International Contexts: Legal Practices and Social Planning toward the Circular Economy. Laws 2021, 10, 3. [CrossRef]

54. Kyriakopoulos, G.L.; Kapsalis, V.C.; Aravossis, K.G.; Zamparas, M.; Mitsikas, A. Evaluating Circular Economy under a Multi-Parametric Approach: A Technological Review. Sustainability 2019, 11, 6139. [CrossRef] 